\title{
Patterning Vasculature: The Role of Biofabrication to Achieve an Integrated Multicellular Ecosystem
}

Citation for published version (APA):

Malheiro, A., Wieringa, P., Mota, C., Baker, M., \& Moroni, L. (2016). Patterning Vasculature: The Role of Biofabrication to Achieve an Integrated Multicellular Ecosystem. ACS Biomaterial Science and Engineering, 2(10), 1694-1709. https://doi.org/10.1021/acsbiomaterials.6b00269

Document status and date:

Published: 01/10/2016

DOI:

10.1021/acsbiomaterials.6b00269

Document Version:

Publisher's PDF, also known as Version of record

Document license:

Taverne

Please check the document version of this publication:

- A submitted manuscript is the version of the article upon submission and before peer-review. There can be important differences between the submitted version and the official published version of record.

People interested in the research are advised to contact the author for the final version of the publication, or visit the DOI to the publisher's website.

- The final author version and the galley proof are versions of the publication after peer review.

- The final published version features the final layout of the paper including the volume, issue and page numbers.

Link to publication

\footnotetext{
General rights rights.

- You may freely distribute the URL identifying the publication in the public portal. please follow below link for the End User Agreement:

www.umlib.nl/taverne-license

Take down policy

If you believe that this document breaches copyright please contact us at:

repository@maastrichtuniversity.nl

providing details and we will investigate your claim.
}

Copyright and moral rights for the publications made accessible in the public portal are retained by the authors and/or other copyright owners and it is a condition of accessing publications that users recognise and abide by the legal requirements associated with these

- Users may download and print one copy of any publication from the public portal for the purpose of private study or research.

- You may not further distribute the material or use it for any profit-making activity or commercial gain

If the publication is distributed under the terms of Article $25 \mathrm{fa}$ of the Dutch Copyright Act, indicated by the "Taverne" license above, 


\title{
Patterning Vasculature: The Role of Biofabrication to Achieve an Integrated Multicellular Ecosystem
}

\author{
Afonso Malheiro, ${ }^{\dagger}$ Paul Wieringa, ${ }^{\dagger}$ Carlos Mota, Matthew Baker, and Lorenzo Moroni* \\ Department of Complex Tissue Regeneration, MERLN Institute for Technology-Inspired Regenerative Medicine, Maastricht \\ University, 6211 LK Maastricht, The Netherlands
}

\begin{abstract}
In regenerative medicine (RM), creating engineered tissues with functionally relevant vasculature is a critical goal. Recent technological advances in biofabrication and bioprinting have been reported which present significant steps toward achieving this aim. While many approaches to address this challenge derive from microfabrication techniques, progress in the material science field and $3 \mathrm{D}$ printing technologies fields have introduced exciting new possibilities for the creation of increasingly complex and functional vascularized tissues. Here, we provide a brief overview of the process of vascularization and its importance within the fields of RM and tissue engineering (TE). We give a brief synopsis of various strategies that have been reported to induce cell patterning for a designed vascular network within a TE construct, including material-based strategies, structural molding approaches, and direct cell-patterning techniques. As well as highlighting advances in the field, we discuss possible areas for further development; in particular, we advocate a combination of strategies to successfully overcome current limitations in developing functional artificial tissues. Overall, the technological innovations in new bioprinting approaches and complementary progress in materials development are recognized as having critical roles as TE matures toward broadly applicable, clinically relevant applications.
\end{abstract}

KEYWORDS: tissue engineering, vascularization, multicellular architectures, bioprinting, multiscale patterning

\section{INTRODUCTION}

The development and improvement of biofabrication techniques have enabled substantial advances in the field of RM. Three-dimensional (3D) biomimetic and patient-specific constructs can now be designed with the aim to fully restore a damaged tissue's functionality. ${ }^{1}$ Although progress toward larger tissue replacements has been made, the inclusion of functional vasculature within these constructs to maintain cell viability is still a great challenge facing the biofabrication/TE field. For this reason, the clinical translation of lab-grown tissues remains limited to thin tissues, such as skin and bladder, ${ }^{2-5}$ which can survive through avascular diffusion of nutrients and oxygen. To transplant thick tissues, the engineered construct must be prevascularized to remain viable, functional, and quickly integrate with the host. ${ }^{6}$

Biofabrication technologies is a promising avenue to address the challenge of prevascularization. ${ }^{7-9}$ Methods such as 3D printing of solid polymers, electrospinning, and stereolitography depend on scaffolds, from natural or synthetic origin, to serve as temporary support for seeded cells, whereas the tissue is forming and maturing. Engineering vascularization within such TE constructs is complicated by the random manner in which cells are seeded and populate the scaffolds. Alternate approaches develop a modular construct by controlled assembly of smaller tissue building blocks. The motivation of these techniques is to mimic the native tissue architecture by directing cell organization, for instance through structures designed to guide cellular self-assembly. Examples of such technologies include 3D bioprinting, inkjet printing, and live cell lithography. Approaches that achieve vascular tissue patterning enable the creation and study of vascular networks through the spatial control over vessel formation.

Patterning capability is an asset not only for improved vascularization but also as we progress toward multicellular systems that can yield functional tissues or complex organ models. Constructs composed of functional cells, the parenchyma, and supporting cells, the stroma, can be sequentially assembled together with the endothelium in order to achieve the multilayered architectural context of an organ. ${ }^{10}$ Additionally, nerve tissue could also be supplied to the construct, which would permit the study of neurovascular interactions. Considering that a full functional tissue is only achieved when innervated, ${ }^{11}$ the combination of a vascular and neural network in a single platform is a significant advance toward a true representation of an organ microenvironment.

Likewise, organoids can also greatly benefit from the presence of vasculature. These miniaturized versions of organs provide accurate anatomical replicas and constitute powerful tools for in vivo simulations, such as drug response. However,

Special Issue: 3D Bioprinting

Received: May 16, 2016

Accepted: July 7, 2016

Published: July 7, 2016 


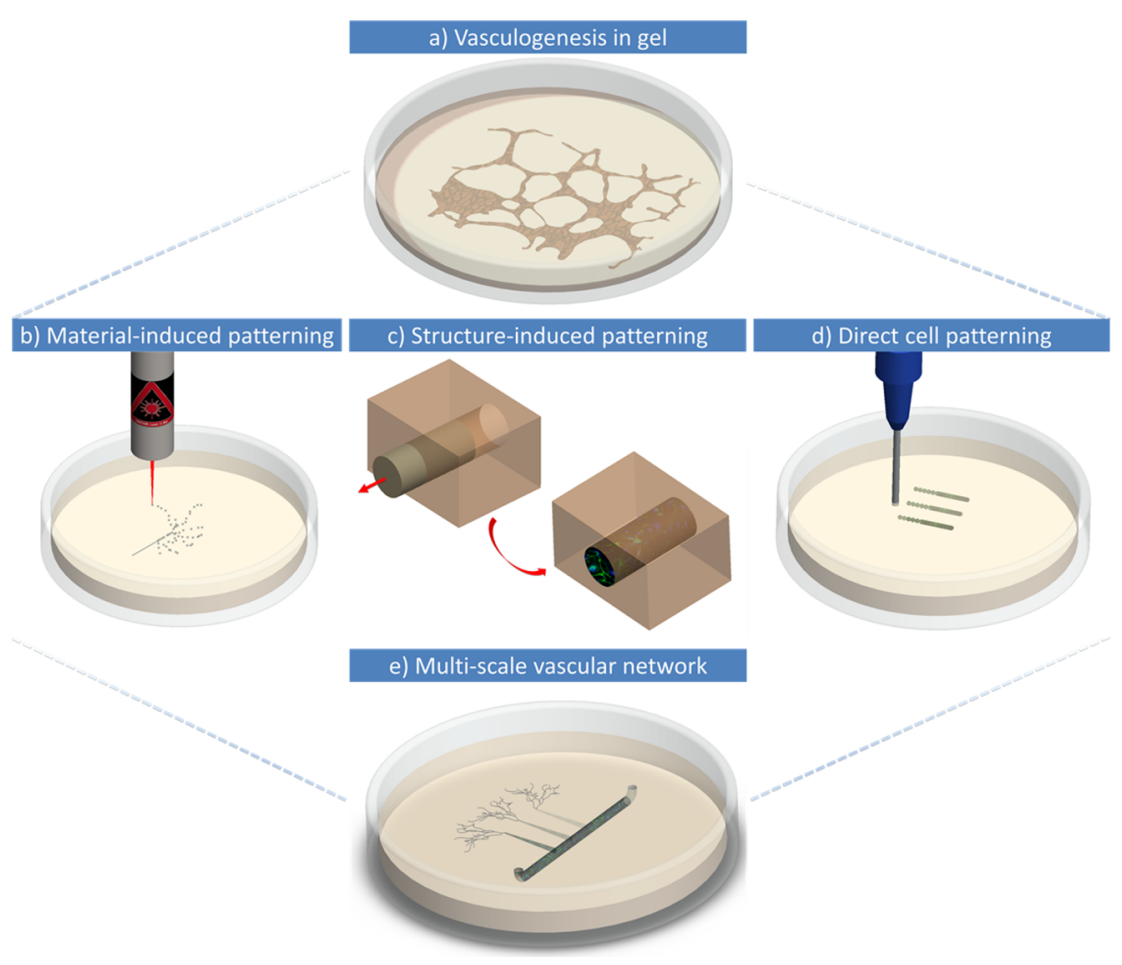

Figure 1. Overview of the classical biofabrication approaches to achieve and pattern vasculature in a TE construct. (a) Spontaneous and uncontrolled self-assembly of vessels from randomly seeded endothelial cells within a bulk hydrogel. (b) Photopatterning of physicochemical cues, for instance, cell adhesion peptides (e.g., RGD), growth factors (e.g., VEGF) and protease-sensible cross-links (e.g., MMP-sensible cross-links) for vessel growth guidance. (c) Vascular channel formation through the removal of a channel template within a hydrogel and subsequent endothelialization (e.g., perfusion with endothelial cells). (d) Bioprinting of cellular spheroids into a biocompatible support (e.g., collagen hydrogel). The spheroids will fuse automatically and self-assemble into vascular structures. (e) Combination of biofabrication approaches to produce a vascular network with multiscale dimensions and clear perfusion accesses. The larger vessel with an inlet/outlet could be fabricate through structure-induced patterning techniques. Smaller vessels emanating from the parent vessel could be produced by direct cell patterning techniques and would provide a bridge to a microvessel pattern achieved through material-induced patterning strategies.

perfusion is required to emulate the dynamic mechanistic environment of cells. ${ }^{12}$ Furthermore, the maturation of progenitor cells used to generate organoids often requires blood flow for the transportation of biochemical cues, such as paracrine signals, which are responsible for establishing communication between cells. In the case of renal organoids, for example, sustained circulation allows the cells to mature and gain functionality in terms of absorption, secretion, and filtration. ${ }^{13,14}$

With these potential applications, strategies to engineer vascularization are a major research focus in the field of biofabrication. Advances in this area may thus address the current limitations of $\mathrm{TE},{ }^{15}$ unlocking the viable fabrication of complex and large implants and contributing to our understanding of synergistic multicellular systems. Here, we provide an overview of biofabrication approaches to create vascular networks as well as discuss the latest developments with a focus on patterning techniques. As summarized in Figure 1, we have categorized approaches to control the development of vascular networks as

- material-induced patterning, guidance of vessel growth through the selective presentation of physicochemical cues, such as cell adhesion peptides, growth factors, protease-sensible cross-links and/or cross-linking density, to cells within a biomatrix

- structure-induced patterning, two-step biofabrication processes that consist of the construction of vessel-like architectures through additive or subtractive manufacturing and further lining with endothelial cells

- direct cell patterning, use of micromolding or printing techniques to assemble vessels by deposition of vascularspecific cells into defined locations

We also consider the limitations inherent to the abovementioned strategies and discuss recent research that aims at tackling these. Finally, some prospects regarding vascular integration within a multicellular ecosystem, multiple length scales needed for functional vascularization, and future expectations of organ development are also discussed.

\section{BIOLOGICAL PROCESSES AND REQUIREMENTS}

In the absence of a capillary network, an implant will rely on diffusional processes for the supply of oxygen and nutrients as well as the removal of metabolites. However, implants of clinically relevant size normally exceed the diffusion limit (approximately $200 \mu \mathrm{m}$ ), leading to the development of a necrotic core and failure to integrate with the host tissue. ${ }^{16,17,8}$ Therefore, the long-term survival of an avascular cell-laden construct strongly depends on rapid neovascularization, the formation of new blood vessels. ${ }^{18}$ An alternative approach is to engineer a vascular network within the tissue implant, which requires a deep understanding of the well-orchestrated natural processes that lead to vessel formation and remodeling. A thorough description of these processes can be found in literature. ${ }^{19-22}$ 
During early embryonic development, de novo formation of blood vessels is achieved through the differentiation of mesodermal progenitor cells in a process termed vasculogenesis. Initially, hemangioblasts located on the yolk sac form focal aggregations designated by blood islands. Within these structures, cells located in the periphery will differentiate into angioblasts, while those in the center will originate hematopoietic cells. Migrating angioblasts self-assemble into aggregates, proliferate, and finally differentiate to form the primary vascular plexus. ${ }^{22,23}$ Postnatal vasculogenesis can also occur during tumor growth or revascularization of damaged tissue, via circulating endothelial progenitor cells (EPCs). This subtype of CD34/VEGFR-2-positive bone marrow-derived angioblasts can be recruited to specific areas and differentiate for in situ vessel growth, in a process promoted by vascular endothelial growth factor (VEGF) and basic fibroblast growth factor (bFGF). ${ }^{22,24}$

In another neovascularization process, angiogenesis forms blood vessels from pre-existing ones; it is the main mechanism during embryogenesis (following creation of the vascular plexus) and adult life. New vessels can be formed from sprouting endothelial cells (sprouting angiogenesis) or through the splitting of other vessels (intussusceptive angiogenesis). ${ }^{23,24}$ We focus on the former process here because it is more relevant to the integration of implants within the host vasculature. Sprouting angiogenesis initiates in response to pro-angiogenic signals that are secreted by local tissues according to their oxygen and nutrient demands. In hypoxic conditions, cells are induced to secrete VEGF, leading to endothelial cell activation and liberation from their matrix support via proteolytic degradation (through secretion of matrix metalloproteinases, MMPs). ${ }^{25,19}$ Subsequently, the Notch pathway controls the specification of endothelial cells into tip or stalk cells via a Notch/DLL4 feedback loop. ${ }^{19}$ Tip cells will lead the sprouting process by sensing their surroundings with filopodia, guiding the sprout via attractive or repulsive signals. ${ }^{26}$ Endothelial cells in close contact will then form a lumen by coalescence of intracellular vacuoles, and new vascular cords are created as soon as migrating neighbor tip cells fuse together. These new vessels remain immature and need to undergo further stabilization steps to become functional. First, perfusion begins by re-establishing a quiescent endothelial phenotype and reshaping the new vessels connections, which are further strengthened by the formation of adherent and tight junctions. Next, maturation steps involve mural cell recruitment and extracellular matrix (ECM) deposition. Pericytes, attracted by the endothelial plateletderived growth factor (PDGF), are recruited to capillaries and adhere to them via the angiopoietin 1 action (ANG1). ${ }^{19}$ For arteries and veins, smooth muscle cells (SMCs) are the stabilization effectors in a process promoted by transforming growth factor $\beta$ (TGF- $\beta$ ). ${ }^{27}$ To complete maturation, we remodeled vessels as a consequence of fluid flow shear stress, which leads to increased diameter and wall thickness (arteriogenesis). ${ }^{24}$

Because of this intricate sequence of events, both vasculogenesis and angiogenesis are slow processes. Thus, host endothelial cell invasion is often not fast enough to promote vascularization within a large implant before its failure. ${ }^{18}$ For this reason, efforts have been made to initiate these vascularization processes within $\mathrm{TE}$ constructs prior to implantation to maintain viable tissue of a clinically relevant size. These endeavors, however, require a veritable source of endothelial cells. Mature cells, such as human umbilical vein endothelial cells (HUVECs) or human microvascular endothelial cells (HMVECs), have been widely researched for this purpose. ${ }^{25,28-30}$ These cells can be easily collected from the umbilical cord or by skin biopsy, respectively, and are relatively simple to culture, forming vascular networks both in vitro and in vivo. ${ }^{30}$ However, expansion of mature cells to sufficient quantity can be a limiting factor due to their low proliferation rate. In comparison, EPCs exhibit an increased proliferation potential and survival rate when compared to their mature counterparts. ${ }^{30,31}$ Late-outgrowth EPCs, also known as endothelial colony-forming cells (ECFCs), participate in tubulogenesis in vitro and have been shown to lead to an accelerated anastomosis in a coculture with fibroblasts when compared to HUVECs. ${ }^{32}$ Large expansion of these cells is a drawback, however, because of the high incidence of cytogenetic alteration. ${ }^{30}$ The other EPCs subtype, the early EPCs, do not form vascular networks but can also contribute to neovascularization through paracrine signals. ${ }^{18,31}$

Vessel maturation and long-term stability are dependent on the addition of supporting cells to the system. Pericytes and SMCs are obvious cell choices, but others such as mesenchymal stem cells (MSCs) and fibroblasts, have been reported to display pericyte-like behavior. ${ }^{33,34}$ Fibroblasts, mostly of dermal origin, have already been successfully cocultured with HUVECs, ${ }^{25}$ HMVECs, ${ }^{29}$ and EPCs, ${ }^{32}$ demonstrating their versatility. In comparison with SMCs and MSCs, fibroblasts (derived from human dermis and mouse 10T1/2 cell line) promoted the formation of a denser vascular network over a 28 day culture period with HUVECs. ${ }^{35}$

\section{PRIOR ART: STANDARD APPROACHES}

To better understand vascular formation, numerous in vitro models have been developed (for a review, see Goodwin ${ }^{36}$ ). Endothelial cells were initially grown on flat substrates of either tissue-culture plastic or on hydrogel surfaces and served to highlight important factors that simulate vasculogenesis and vascular morphogenesis, such as ECM components (i.e., laminins) and the pro-vascularization factors VEGF and bFGF. ${ }^{36}$ In lieu of the presence of growth factors, cocultures with suitable mural cells have also been able to stimulate endothelial cells to form vascular networks. ${ }^{37}$

Because two-dimensional (2D) substrates intrinsically limit the formation of $3 \mathrm{D}$ vascular structures, researchers began to encapsulate cells within hydrogels of reconstituted ECM proteins to better approximate the protein composition and 3D environment found in vivo (Figure 1, top panel). Proteinaceous gels made from collagen, fibrin, or Matrigel (a tumor-derived ECM) have been critical in initiating the vascularization processes within a $3 \mathrm{D}$ context. Synthetic hydrogels can also support vessel formation, but they must emulate natural ECM materials in terms of being cell adhesive, sufficiently soft, and susceptible to cellular remodeling to allow for cell migration and self-assembly of vasculature. ${ }^{38}$

When in vitro vascularization is initiated with appropriate $3 \mathrm{D}$ environments, vascular formation is more comparable to that of the in vivo state. ${ }^{39}$ Furthermore, endothelial cells grown in 3D exhibit enhanced matrix-remodeling capabilities, a critical mechanism in angiogenesis. ${ }^{40}$ Compared to $2 \mathrm{D}$ substrates, $3 \mathrm{D}$ environments can also stimulate endothelial cells from a wider variety of sources to form capillaries, ${ }^{41}$ and the resulting networks are stable for a longer period of time. However, similar to the $2 \mathrm{D}$ culture systems, endothelial monocultures 


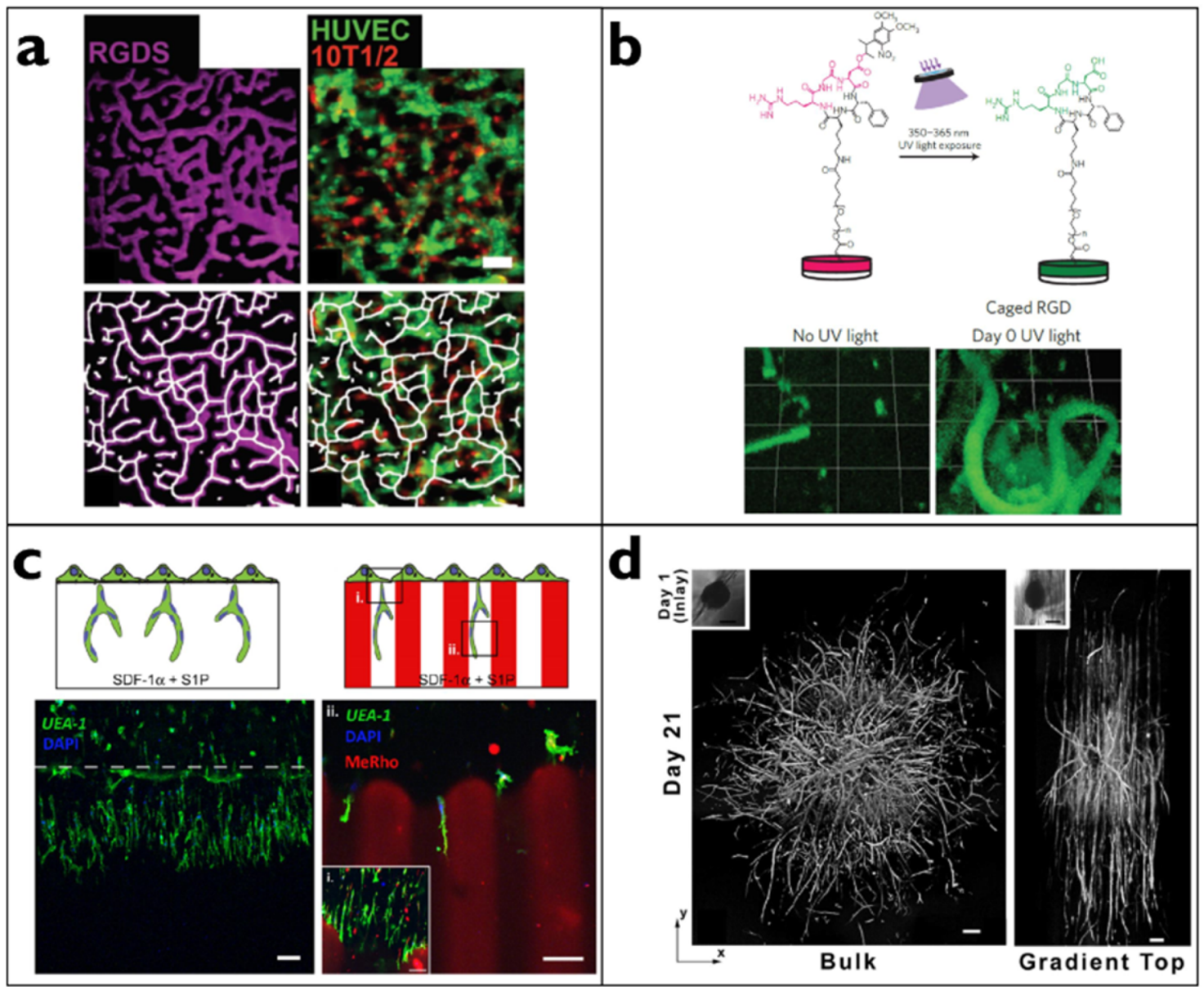

Figure 2. Shown are leading examples of materials based patterning of vascularization. (a) Control over the covalent photopatterning of RGD within a degradable PEGDA based hydrogel has been shown to recapitulate biomimetic networks of vascularization. ${ }^{57}$ (b) Through judicious use of photolabile protecting groups, the patterning of RGD sites within a hydrogel can be effected after fabrication of the hydrogel with success in directing vascular formation subcutaneously in mice. ${ }^{58}$ Additionally, patterning of MMP cleavable hydrogels (c) with networks that are "permissive" and "nonpermissive" to cellular remodelling has shown to be an effect strategy for the directing the vascularization of ECFC clusters. ${ }^{59}$ In an interesting example, complex gradients (d) of MMP cleavable cross-links, RGD concentration, and VGEF concentration have been shown to provide directionality to the growth of vascular networks in hydrogel materials. Surprisingly, these vessels are formed bidirectionally along the gradient, i.e., high-to-low and low-to-high directionality. ${ }^{61}$ Scale bars: (a) 50, (c) 100, and (d) $200 \mu \mathrm{m}$.

undergo a more efficient capillary formation in the presence of angiogenic factors. Studies have shown that VEGF-releasing hydrogels, ${ }^{42}$ hydrogels with covalently bound VEGF, ${ }^{43}$ and hydrogels with covalently bound VEGF peptide mimetics ${ }^{44}$ are all capable of inducing vascularization in otherwise inert polyethylene glycol (PEG)-based systems. Strategies such as these, along with adhesive properties and MMP sensitivity, have been recently thoroughly reviewed. ${ }^{45}$

Alternatively, vascular networks will spontaneously form when endothelial cells and appropriate mural cells are cultured together within the hydrogel, with the mural cells providing both angiogenic factors and, crucially, integrating with newly formed vessels to stabilize and further mature nascent vasculature. ${ }^{33,46}$ In addition to dissociated cells, the culturing of aggregates of cells or explanted tissues within hydrogels has enabled the study of angiogenesis, whereby vessels extend from the aggregate into the surrounding gel. ${ }^{36,47}$ Known as the sprouting assay, this is also used to study the process of anastomosis where sprouting vessels connect with one another. Again, the successful formation of sprouts requires either the addition of growth factors or the presence of other supporting cells types. These techniques to create $3 \mathrm{D}$ vascular in vitro models have also been applied to the vascularization of tissue scaffolds as a means to improve the viability of implanted constructs $^{48,49}$ or as cell-based angiogenic therapies for treatment of tissues that have become ischemic, such as the myocardium. $^{50}$

Similar to the 3D culture platforms described above, implantable tissues have been embedded within carrier hydrogels in combination with supporting cells, such as HUVECs and hMSCs, to encourage prevascularization and promote anastomosis. ${ }^{51,52}$ However, this approach lacks control over the size and distribution of vessel formation, risking delayed anastomosis of the tissue and reduction in delivery of oxygen and nutrients within the implant.

\section{IMPORTANCE OF CELL PATTERNS}

The strategies described above rely on the uncontrolled addition of endothelial and supporting cells as a way to induce vascularization within a TE construct, which poses some limitations. With all cells having a random starting position, vascular morphogenesis will be dependent on the spontaneous self-organization of endothelial cells. ${ }^{24}$ Under this condition, neovascularization seems to occur initially via the formation of 
endothelial clusters in a vasculogenic-like process, followed by extensive sprouting. Subsequently, vascular networks are formed as a combination of sprout anastomoses or cluster thinning. ${ }^{25}$ Although this results in vasculature, this is a timeconsuming process that might prove too slow to supply the demands of a thick implant. Moreover, network formation occurs in a random manner and is characterized by nonuniform rate, length, diameter, and tubule orientation, which results in a network with a tortuous morphology, dense interconnectivity, and possibly distanced more than $200 \mu \mathrm{m}$ from tissue-specific cells. ${ }^{53}$ This random network also does not offer any clear location for natural or surgical anastomosis, which may result in delayed perfusion. ${ }^{24}$ Finally, in a natural setting, the blood flows from macro- to microvessels, which allows the conservation of shear rate at bifurcations, as described by Murray's law. If the shear rate falls below a certain threshold, which can occur when parent and daughter vessels have the same diameter, thrombus formation can occur and perfusion is lost. This problem has been reported in a prevascularization strategy using unpatterned cell-embedded hydrogels. ${ }^{54}$

To address some of these problems, recent efforts have focused on controlling cell localization as a strategy to improve neovascularization within a TE construct. Cell-patterning techniques bring several advantages. First, vessels can be assembled faster. Second, patterning can direct vessels to resemble the natural vascular tree in order to maintain a shear rate above the thrombogenesis onset. Third, patterning can recapitulate native vessel-tissue architecture (e.g., liver microarchitecture) and to ensure its distribution complies with the diffusion limit. ${ }^{53,8}$ Larger patterned structures, forming macrovessels, may provide clear locations for surgical anastomosis, thus leading to a faster perfusion of the implant and good host integration. Lastly, patterning techniques facilitate the combination of a bioreactor with a TE construct, in which an inlet/ outlet can be employed to dynamically seed cells, provide fluid flow within the construct (essential step for vessel maturation), and/or administer drugs until the point of implantation. ${ }^{55,10}$ The following sections will review different strategies to induce vessel patterning through materials modification, structural guidance, and direct cell deposition.

\section{MATERIAL-INDUCED PATTERNING}

The development of new materials has been pursued to direct and to spatiotemporally control the formation of vascular networks. Materials-based control of the vascular ingrowth at a molecular level remains one of the most promising patterning strategies. Toward this aim, several prominent materials-based strategies have been successfully employed to guide and direct vasculature formation in 2D and 3D space as depicted in Figure 2.

Currently, spatiotemporal control of vascularization is most commonly effected through patterns of growth factors, adhesive peptides (e.g., RGD), cross-link density and/or patterns of MMP-degradable cross-links (Figure 1b)). As already discussed, growth factors such as VEGF have a direct influence on both vasculogenic and angiogenic processes. Therefore, their presentation to cells in predefined patterns can potentially provide control for region-specific cell differentiation and over sprouting direction. Sprouting angiogenesis anisotropy could also be harnessed with patterning of cell adhesion peptides and MMP-sensible cross-links, which are both required for endothelial cell migration.
For example, Leslie-Barbick and co-workers ${ }^{56}$ demonstrated that the photopatterning of covalently bound VEGF and RGD within a PEG diacrylate (DA) hydrogel network directed the formation of tubular-like endothelial cell organization with significant upregulation of angiogenic genetic markers. Exhibiting the ability of this approach to recapitulate complex architectures, Culver and co-workers ${ }^{57}$ recorded the vasculature of several model tissues (retina, cerebral cortex, and heart) via confocal imaging and patterned into 3D hydrogels. Within an MMP-cleavable PEGDA network, covalently bound RGD was patterned via two-photon polymerization to match the architecture of the tissue vasculature. When this patterning of RGD was effected in hydrogels laden with HUVECs and 10T1/ $2 \mathrm{~s}$ fibroblast-like cells, the coculture organized into complex tubule-like networks that overlaid remarkably well with the biomimetic patterns (Figure 2a). In another work utilizing RGD patterning, Lee and co-workers ${ }^{58}$ successfully transferred a VEGF-containing hydrogel capable of inducing vasculogenesis $^{42}$ into a photopatternable system capable of directing vasculogenesis in vivo. Utilizing a caged RGD sequence (photolabile 3-(4,5-dimethoxy-2-nitrophenyl)-2-butyl ester (DMNPB)), they were able to exhibit spatial control over the presentation of RGD and direct the migration of cells within the biomaterial (Figure 2b). This system allows real-time modification of the biomaterial; consequently, they showed that spatiotemporal regulation of RGD presentation within VEGFcontaining hydrogels was able to direct vascularization to specific locations of the hydrogel when implanted subcutaneously in mice.

In addition to the patterning of cell-adhesive molecules and growth factors, spatial control over the degradation of the material can also be utilized to guide vessel formation. In a study by Hanjaya-Putra and co-workers, ${ }^{59}$ acrylated hyaluronic acid (HA) was cross-linked with MMP-sensitive cross-links and functionalized with RGD. In the absence of photopolymerization, cell-remodelable hydrogels were formed that allowed vasculogenesis, whereas photopolymerization created a nondegradable network that blocked vasculogenesis in both in vitro and in vivo models. Both hydrogels allowed vacuole and lumen formation; however, the photo-cross-linked hydrogel did not allow branching, sprouting, or network formation. By photopolymerizing sections of a hydrogel in the presence of a mask, controlled and directed angiogenesis from ECFCs seeded on top of the hydrogels was demonstrated (Figure 2c). In a step toward selectivity of hydrogel remodeling for vascularization, research to determine the effect of MMP cleavage-site specificity on vascular ingrowth has shown promising results in vitro, yet all materials showed similar results in vivo. ${ }^{60}$

Although the "off/on" patterning of materials has been shown to enable directional vascularization within hydrogels, the utilization of gradients within materials is less explored. In a telling example, Turturro and co-workers ${ }^{61}$ fabricated PEGDA hydrogels with concurrent gradients of stiffness, susceptibility to MMP cleavage, and RGD density via a gradient polymerization technique. When compared to bulk polymerized hydrogels, those formed via gradient polymerization showed increased directionality of formed vascular networks when populated with HUVEC and human umbilical artery smooth muscle cell (HUASMC) aggregates (Figure 2d). Interestingly, in areas with the highest network density and highest concentration of RGD, vascularization was affected along the gradient of the material-vascularization occurred bidirectionally from high-to-low and low-to-high density areas. The exact 


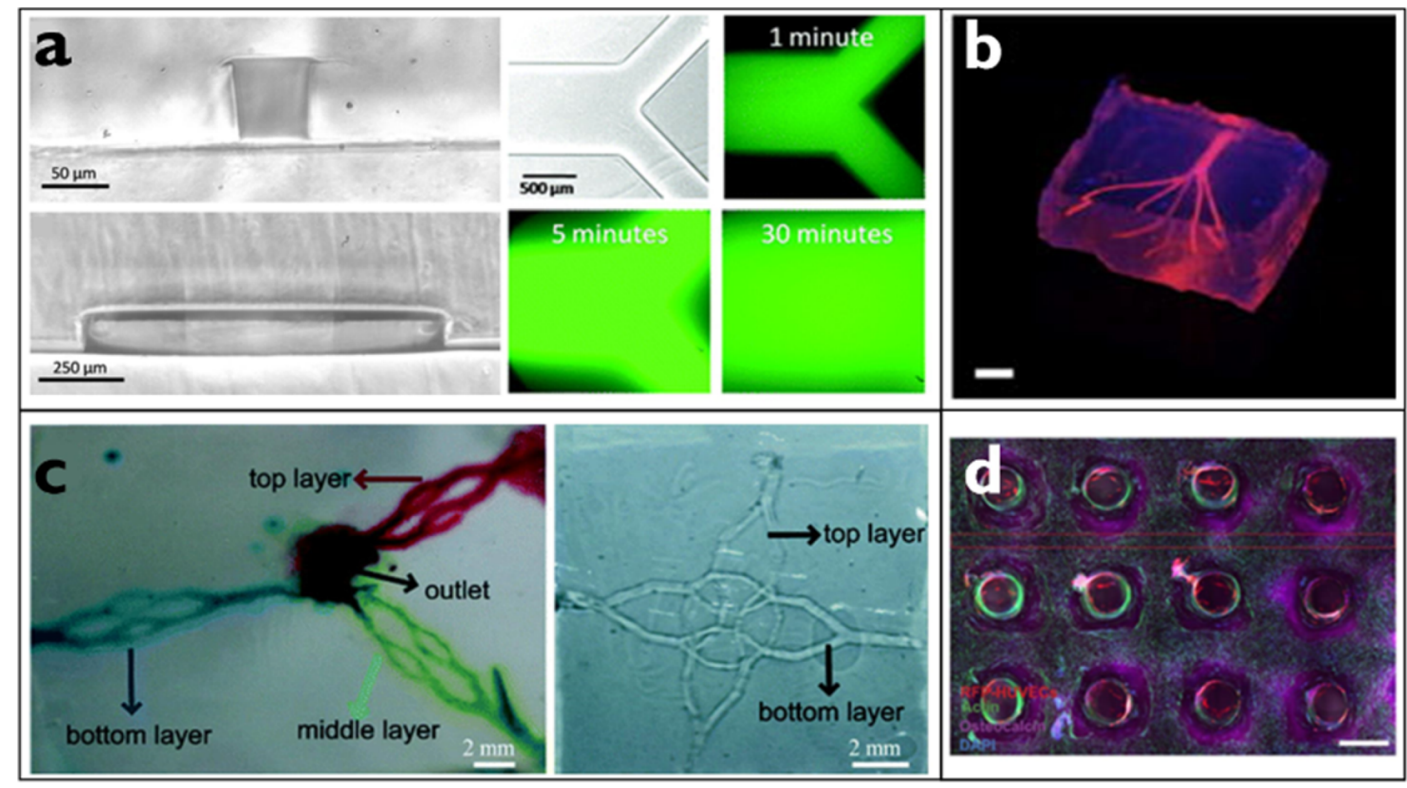

Figure 3. Selected strategies for structure-induced vascularization. (a) Light micrograph cross sectional images showing channel fidelity and the layer-by-layer interface between hydrogel films of agarose. (top left) A channel $50 \mathrm{um}$ in width $70 \mathrm{um}$ in height and (bottom left) $1 \mathrm{~mm}$ in width 150 um in depth are depicted. Diffusion over time of FITC-BSA into the surrounding agarose gel (right). ${ }^{73}$ (b) Extruded agarose "wires" are used to form microchannel within gelatin (top), shown here with a perfusion of red microbeads in solution. ${ }^{79}$ (c) An alginate hydrogel formed in a PDMS mold is embedded within gelatin and dissolved using EDTA, resulting in perfusable microchannels (right). A triple layer 3D microfluidic network in gelatin, perfused with different colors (left). ${ }^{86}$ (d) A 3D printed sacrificial template of Pluronic F-127 is intercalated between bioprinted hMSCs and the whole structure is embedded in a fibroblast-laden matrix. The sacrificial ink is then removed and the structure perfused with endothelial cells to produce vasculature surrounding the parenchymal and stromal tissue. ${ }^{131}$ Scale bars: (b) $3 \mathrm{~mm}$ and (d) $1.5 \mathrm{~mm}$.

mechanisms of this polarization are currently unknown, but follow-up research has shown that stable gradients of VEGF within hydrogels can consistently increase vascularization depth in in vivo-implanted hydrogels relative to nongradient hydrogels. ${ }^{62}$ Using multiphoton laser patterning, Aizawa et al. created a covalently bound gradient of VEGF within a hydrogel to direct angiogenic activity. ${ }^{63}$ In addition, it is well-known that gradients of oxygen concentration are able to direct vascularization toward the hypoxic area. ${ }^{64}$ Gradients have consistently been shown to affect the vascularization propensity of hydrogels, but remain an underexplored and promising variable to consider when engineering instructive materials for tissue regeneration.

Much work remains to be done toward the spatiotemporal control of vascularization within tissue-engineered constructs and biomaterials. Although the above approaches have made significant progress, specificity and selectivity are needed when attempting to recreate vasculature within complex tissue with multiple cell types. In this regard, gradients and/or patterning of VEGF- or MMP-cleavable sites specific for vascularization may be the most promising, because vascularization networks will be competing with other cell types for adhesion and proliferation.

\section{STRUCTURE-INDUCED PATTERNING}

To engineer a vascular pattern, a number of techniques have evolved that produce structural patterns of microchannels, which provide a designed $3 \mathrm{D}$ architecture to localize endothelial cells and direct self-assembly of microvessel networks. The beginning of this "structural patterning" can be traced to the field of microfluidics, which employs rigid microfabricated molds to transfer microchannel structures to softer polymeric materials and create well-defined micro- channels; a brief review by Kim et al. provides and overview of the field. ${ }^{65}$ Although microfluidic devices are attractive tools for vascularization studies (reviewed by Smith et al. ${ }^{66}$ ), they are typically fabricated from polymers that do not mimic the native biological environment. This has prompted the integration of cell-laden hydrogels within microfluidic devices for an improved in vivo approximation. Initial strategies relied on vasculogenesis to create perfusable vessel networks, ${ }^{67-69}$ enabling the study of nutrient transport ${ }^{70}$ and revealing that the application of flow itself can induce formation of vasculature. ${ }^{71}$ Because these microvessels take time to develop and are random in nature, various techniques aim to accelerate the formation of designed vascular networks by incorporating guiding microchannel structures within biomimetic hydrogels. Such structures resemble the vessel lumens and once they are populate with an endothelial cell layer, a vascular network microarchitecture can be achieved much faster than through random cell self-assembly. Figure 3 provides an overview of these structure-induced patterning techniques, classified into three main categories in the discussion below: layer-by-layer film casting; removable template molding; sacrificial templating.

Layer-by-Layer Film Casting. The layer-by-layer approach casts a polymer solution onto microfabricated molds to produce a biocompatible hydrogel layer with microchannel structures. These layers are then placed on top of a flat substrate to form an enclosed, perfusable channel network. Numerous hydrogel materials have been used to create microfluidic devices, ranging from the bioinert alginate ${ }^{72}$ and agarose $^{73}$ (Figure 3a) to the intrinsically cell-adhesive fibrin and collagen. ${ }^{74}$ These studies report microchannel sizes from 20 $\mu \mathrm{m}^{74}$ to $1000 \mu \mathrm{m},{ }^{73}$ all of which have been shown to maintain the viability of cells encapsulated within the bulk of the hydrogel. This technique is particularly promising to recreate 
the in vivo setting of endothelialized vessels surrounded by mural cells. Starting with fibrin or collagen gels laden with mural cells, it has been shown that such microchannel systems can be seeded with endothelial cells to form a structurally patterned vessel-like organization.

Although traditional microfluidic materials can be bonded to a substrate to create a sealed perfusable system, hydrogel films must be either placed in a specialized apparatus that mechanically maintains a seal ${ }^{75}$ or two gel surfaces must undergo localized depolymerization, placed against one another, and then repolymerized to form a bond. ${ }^{72-74}$ By employing a microfabricated mold, precise and intricate designs can be achieved of interconnected networks of microchannels with a wide range of dimensions. However, this micromolding approach intrinsically limits this technique to planar microchannels designs, in contrast to the arborized 3D vessel structures observed in vivo. Furthermore, the cumbersome assembly and sealing of such a layer-by-layer hydrogel device restricts the broader application of this approach.

Removable Template Molding. Microchannels were first formed within a monolithic hydrogel construct by forming the gel around removable channel templates, such as wires or needles (Figure 1c)). Acellular collagen gels formed in this way have been used as nutrient beds, with emulated blood flow to support multiple layers of cultured cells. ${ }^{76}$ This improved the viability of thick $(\sim 100 \mu \mathrm{m})$ layers of cells; endothelial cells from the cell layer were shown to migrate and surround the microchannels in a manner reminiscent of vasculature. Similar devices made of gelatin methacrylate (GelMA), a photo-crosslinkable collagen derivative, were shown to support both the encapsulation of fibroblasts within the gel and the seeding of endothelial cells within the microchannels for a more direct recreation of vascular structures. ${ }^{77}$

The need to physically remove templates from fragile hydrogels typically requires these molding structures to be nonadherent, to be sufficiently large and strong enough to be manually extracted. To preserve the integrity of the encasing structure, most reported strategies employ channel templates with a straight shape such as rigid wires or needles with diameters ranging from 76 to $300 \mu \mathrm{m} .^{77,78}$ In place of a novel approach encapsulates flexible agarose "wires", 250 to $1000 \mu \mathrm{m}$ in diameter, within GelMA ${ }^{79}$ (Figure $3 b$ ). Agarose does not adhere to the gelatin and, at these diameters, has sufficient strength to be manually extracted. Furthermore, channels with slight curvatures are also possible. In this system, osteoblasts were encapsulated within the GelMA and perfused endothelial cells formed a monolayer on the microchannel wall. José et al. recently reported vessels with $45^{\circ}$-angled bifurcations can also be patterned, by pulling out flexible polydimethylsiloxane (PDMS) rods from a collagen medium. These materials do not adhere to one another, permitting template removal and formation of an open channel network that can be further endothelialized. ${ }^{80}$

While the formation of microchannels via the methods described can create endothelialized microchannel within a single, monolithic segment of hydrogel, this cannot easily realize an intricately designed, interconnected microchannel networks as achieved through film casting. Furthermore, the need to extract the removable molds restricts channel size and limits design complexity.

Sacrificial Molding. A versatile alternative molding strategy using a sacrificial template to create complex microchannel networks. In this approach, the template structure is fabricated, embedded within a hydrogel precursor, and later dissolved after the hydrogel is cross-linked. Bellan et al. reported on the formation of microchannels within a biocompatible gelatin hydrogel construct, achieved by embedding Shellac microfibers and later removing them via degradation in an ammonia bath. ${ }^{81}$ A more recent example employs water-soluble poly(vinyl alcohol) (PVA) cast in a PDMS mold to form well-defined sacrificial templates. ${ }^{82}$ This template was embedded within a nonaqueous hydrogel precursor to prevent premature PVA dissolution, followed by thorough washing with water and PBS after cross-linking to extract any nonaqueous solvents and the PVA template. A novel method of creating suitable sacrificial template was reported by Huling et al., ${ }^{83}$ where the preserved vascular tissue of a mouse kidney was used to cast a polycaprolactone (PCL) template. This template was later coated with a layer of cross-linked collagen and the PCL was dissolved with acetone. While unique in its recreation of the arborized and multiscale vascular pattern, the final hollow 3D structure of thin collagen restricted cell seeding to the outside of the microchannel structures. In general, these approaches require harsh conditions to form the microarchitecture, limiting the introduction of cells to when device fabrication is complete.

To make sacrificial templates resilient to the aqueous conditions of cell-laden hydrogels, a few studies have taken water-soluble structures and coated them with a biocompatible water-insoluble layer of poly(DL-lactide-co-glycolide) (PDLGA). ${ }^{82,84}$ Miller et al., in particular, have elegantly combined this approach with the 3D printing of an organized lattice of carbohydrate glass microfilaments, ranging in size from 150 to $750 \mu \mathrm{m}$. ${ }^{84}$ Although this study produced microchannels in cell-laden hydrogels and reported angiogenesis as endothelial cells within the channels invaded the surrounding hydrogel, a major drawback of this approach is the residual barrier of the PDLGA sheath on the microchannel perimeter. To create microchannel structures without the use of protective polymer layers or harsh dissolving agents, alginate can be used as the sacrificial material. In a recent report, a crosslinked alginate template was created, then disrupted using either sodium citrate or alginate lyase, resulting in $40-\mu \mathrm{m}$ channels within a fibrin gel. ${ }^{85}$ This process retained the viability of embedded cells dissociated from cardiac tissue, with the endothelial cells of this mixed population observed to migrate and populate the lumen of the microchannels. Ethylenediaminetetraacetic acid (EDTA) has also been used to liquefy alginate and form microchannels from 20 to $500 \mu \mathrm{m}$ in diameter with collagen, gelatin, or agarose ${ }^{86}$ (Figure 3c). Although this approach is capable of multilayered 3D microchannel architecture and supports the seeding of endothelial cells within the microchannels to form vascularlike structures, compatibility with embedded cells has not been shown.

Solubilizing agents are avoided altogether by using sacrificial templates that liquefy in response to temperature changes. One study formed and embedded a gelatin template at room temperature, later raising the temperature to $37{ }^{\circ} \mathrm{C}$ to liquefy the gelatin and form microchannels. ${ }^{87}$ The embedding matrices reported include collagen, Matrigel, and fibrinogen, with fibroblasts hosted within the gels and endothelial cells perfused within the channels. The gelatin templates were fabricated with a PDMS mold, leading to microchannels ranging from 6 to 50 $\mu \mathrm{m}$ in width. Lee et al. have alternatively devised a $\operatorname{poly}(\mathrm{N}$ isopropylacrylamide) (PNIPAM) template strategy that requires cooling from 37 to $32{ }^{\circ} \mathrm{C}$ to liquefy and remove the 

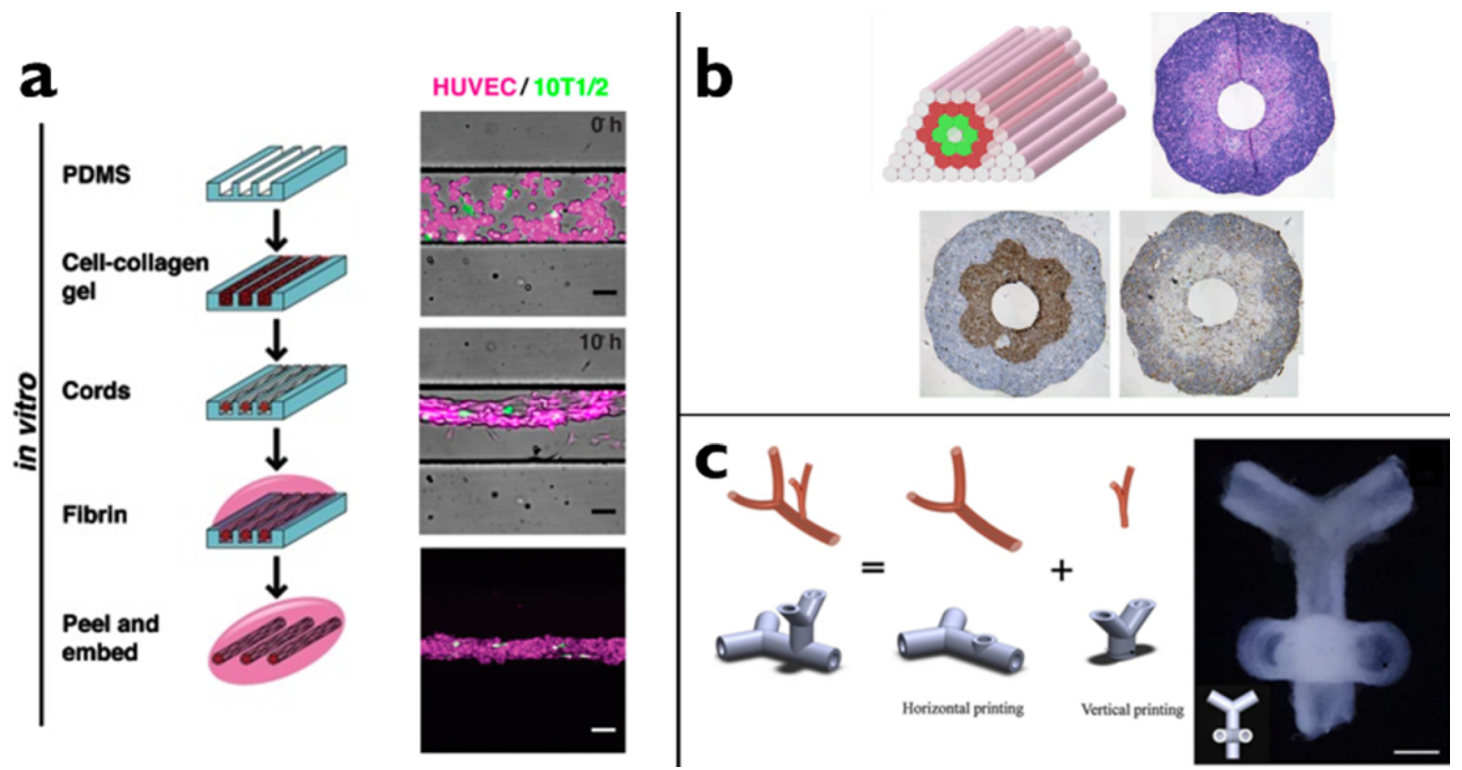

Figure 4. Selected strategies for the fabrication of vascularization utilizing cell patterning. (a) Left: Schematic representation of the vascular cords assembly through a micromolding technique. Right: Self-assembly of HUVECS and 10T1/2 fibroblasts into vascular cords happens within 10 h. ${ }^{53}$ (b) 3D printing of concentric multicellular cylinders (top left) enables the formation of a double-layered vascular tube (green represent SMCs and red represents fibroblasts). Histological examination of the tubes after 3 days of fusion show H\&E (top right), smooth muscle $\alpha$-actin (brown, bottom left), and Caspase-3 (brown, bottom right). ${ }^{95}$ (c) Free-from inkjet printing of sodium alginate and fibroblasts into a bath of calcium chloride enables the fabrication of cell-laden tubular structures with bifurcations, creating well-defined tubular structures with vascular cell type. ${ }^{100}$ Scale bars: (a) $50 \mu \mathrm{m}$ and (c) $3 \mathrm{~mm}$.

template. ${ }^{88}$ This permits faster gelation at $37{ }^{\circ} \mathrm{C}$ for hydrogels such as collagen or Matrigel, ensuring the viability and homogeneous distribution of encapsulated cells. Although this work reported microchannels ranging from 35 to $100 \mu \mathrm{m}$ in diameter and maintains the viability of encapsulated fibroblasts, no seeding of endothelial cells was described. This could be attributed to the highly random organization of the microchannel network produced, which could have hampered cell seeding.

To achieve a more designed capillary network, thermoresponsive materials such as Pluronic F-127 can be printed directly to fabricate a custom-designed sacrificial pattern with highfidelity. These patterns can also be printed in combination with other cell-laden bioinks and further embedded within celladhesive hydrogels, such as GelMA. ${ }^{89}$ Upon cooling to $4{ }^{\circ} \mathrm{C}$, the pluronic material undergoes gel-to-fluid transition, resulting in an empty channel networks that offers precise locations for perfusion with endothelial cells. Applying this strategy, Kolesky et al. demonstrated its potential by fabricating a large and vascularized tissue construct. Here, the authors used 3D printing to pattern hMSCs in a lattice that was intercalated with Pluronic F-127. These structures were further encapsulated in a gelatin/fibrinogen mixture carrying human fibroblasts, followed by fugitive ink removal and endothelialization of the network (Figure 3d). To assess the vasculature functionality and develop a bonelike construct, we perfused osteogenesisinducing biomolecules and the resulting expression of bone markers evaluated. The vascularized scaffolds stained positively for collagen type I and osteocalcin, and showed a much denser formation of mineralized matrix compared to the avascular control. $^{10}$

Overall, sacrificial molding methods present a versatile approach to create microchannel structures, but are generally restricted to either planar or completely random networks. For this reason, advances in bioprinting techniques hold great promise in terms of improved 3D design capabilities and integration with additional tissues

\section{DIRECT CELL PATTERNING}

Techniques that can control cell localization, from multicellular clusters to single cells, have also been utilized in the construction of vascular networks (Figure 4). These techniques make use of the potential for cell self-assembly and autonomous organization into blood vessels to generate vascular patterns. Controlled cell deposition, such that cells are in close proximity to one another, can decrease the time required for cellular selfassembly while simultaneously guiding the direction of lumen formation. ${ }^{90}$ Direct cell patterning technologies encompass cell molding, 3D bioprinting, inkjet printing, laser-assisted bioprinting ( $\mathrm{LAB})$, and optical guide/tweezers.

Cell-laden hydrogels are used in tissue micromolding techniques to create geometrically defined and multiscale vessels. Baranski et al. showed this by seeding a mixture of HUVECs and fibroblasts in liquid collagen into $150-\mu \mathrm{m}$-wide microchannels of a PDMS mold, where the cells would selfassemble into vascular cords ${ }^{53}$ (Figure 4a). These were subsequently peeled off and embedded in a fibrin hydrogel, prior to implantation in mice. Patterning vasculature within the construct proved to be beneficial, given that compared to the randomly seeded construct, the former yielded a faster anastomosis with the host, improved vascular network formation, and required a fewer number of cells. Another example was shown by Nikkhah et al., where photomasked channel patterns were formed from cell-laden GelMA, resulting in the formation of vascular cords with a diameter proportional to the channel width. ${ }^{91}$ Micropatterning techniques, although capable of providing precisely tuned vascular channels, require a plastic support for their formation, which impedes the blend of other tissues within the vasculature and does not provide the ability to recapitulate multi- layered tissue organization. 

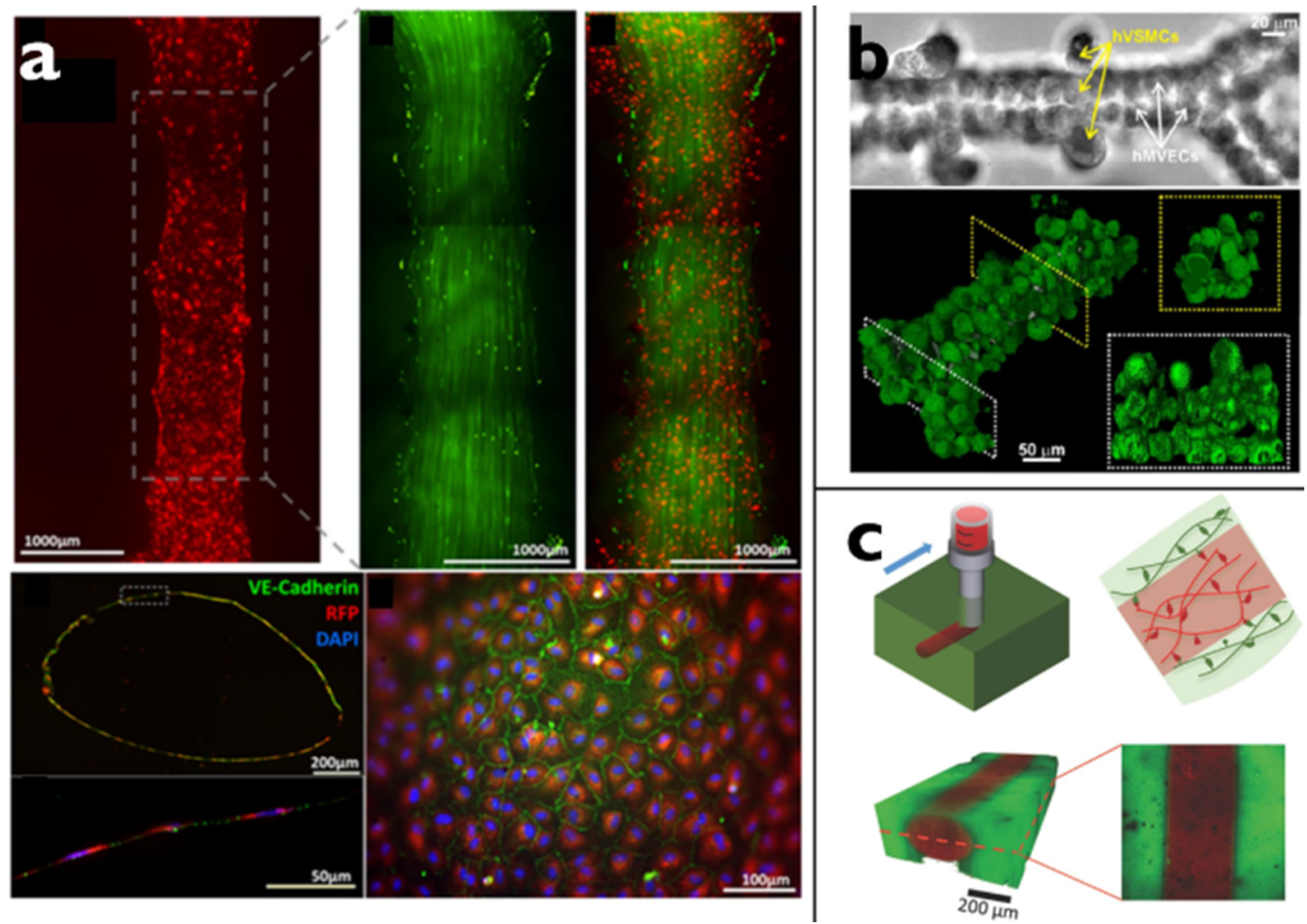

Figure 5. Current approaches utilizing a combination of techniques for vascularization. (a) Fluorescence imaging of a printed vascular channel fabricated in layer by layer deposition after 1 day of culture on dynamic flow conditions (top, HUVECs are shown in red, flow beads are shown in green). Good monolayer formation is exhibited by fluorescence imaging of both cross sections of this channel (middle left and bottom left) and the surface of the channel (bottom right, DAPI staining is blue, RFP-transfected HUVECs are red, VE-cadherin staining is green). ${ }^{109}$ (b) Fabrication of a synthetic capillary via live cell lithography. ${ }^{106}$ Using optical tweezers and photopolymerizable hydrogels, clusters of different cell types can be positioned with great precision and accuracy. (c) Supramolecular interactions allow self-healing and shear-thinning cell-laden materials. ${ }^{114}$ Here, one cell-laden material (guest, red) can be printed into another cell-laden material (host, green) that deforms to accommodate the ink and self-heals to maintain its position.Patterning.

A classical approach relies on the formation of spheroids, multicellular aggregates that can be used as building blocks to construct tissues. ${ }^{92}$ A simple demonstration for vessel assembly consisted on casting vascular spheroids in collagen hydrogels to induce vascular fusion. ${ }^{93}$ The VEGF-treated E8.5 mouse allantois-derived spheroids fused together as coalescent droplets, resulting in the formation of a single lumen and SMCs layer. Control over spheroid location is crucial for efficient vessel assembly, design, and integration with other tissues. This can be provided by 3D bioprinting, which allows for controlled extrusion of material to generate custom-made patterns (Figure 1d). Jakab et al. reported the 3D bioprinting of spheroids into collagen gels which served as support (biopaper) for their assembly. ${ }^{94}$ However, uneven gelation and collagen incorporation into the cellular construct led the researchers to replace collagen with agarose ${ }^{95}$ (Figure 4 b). Although using spheroids for tissue formation is a simple approach, several drawbacks exist, including the need for several spheroid units, their large size $(\sim 300 \mu \mathrm{m})$, long fusion times, and resulting inhomogeneous structures. ${ }^{95}$ The slow kinetics of spheroid fusion was probably due to the agarose substrate, because this parameter has been described to depend on matrix chemical and physical properties. ${ }^{5}$ To circumvent this, the same authors used concentric multicellular cylinders composed of SMCs (inner layer) and fibroblasts (outer layer) to fabricate a vascular tube, representing a macrovessel with tunica media and adventitia, which could be later perfused.
The assembly of vascular channels has been achieved by $3 \mathrm{D}$ bioprinting approaches using both natural and synthetic hydrogels as cell carriers. Cell extrusion within ECM-mimicking biomaterials has also been achieved where fibroblasts were encapsulated in gelatin or multiarm PEG, both premodified with HA. ${ }^{96,97}$ Tubes were built either by vertically printing around acellular layers of $\mathrm{HA}^{96}$ or by horizontal deposition on agarose rods. ${ }^{97} 3 \mathrm{D}$ bioprinting technologies may provide the tools to assemble functional large- to medium-sized blood vessels in vitro. However, generation of a dense microvascular network resembling the native situation is yet to be accomplished, as a consequence of the low resolution that current systems offer.

In contrast to $3 \mathrm{D}$ bioprinters, inkjet printers have the advantage of high resolution, delivering picoliter droplets with an accuracy of a few micrometers. ${ }^{98}$ Both the thermal and piezo modality have been used with some success to fabricate vessellike shapes. ${ }^{99,100}$ Fibrin strands containing HUVECs with a width smaller than $100 \mu \mathrm{m}$ could be formed by thermal inkjet printing of a cell-thrombin solution within a fibrinogen substrate. ${ }^{99}$ The cells proliferated, aligned in the channels, and showed some integrity when patterned in ring structures. Christensen et al. developed a more complex design that featured a support-free construction of tube with bifurcations as well as horizontal and vertical components ${ }^{100}$ (Figure 4c). One drawback of inkjet printing systems is it requires low viscosity 
solutions to prevent nozzle clogging, thus limiting the choice of materials and range of cell densities. ${ }^{98}$

These material restrictions are not an existing issue for $\mathrm{LAB}$, since it is a nozzle-free system and therefore allows the printing of droplets with various viscosities $(1-300 \mathrm{mPa} / \mathrm{s})$ and cell densities. ${ }^{8}$ LAB has been used to pattern a microvascular network with a stem and branches composed of HUVECs. ${ }^{101}$ After 1 day of culture, the cells were seen to stretch out and establish connections with each other that resulted in lumen formation. Lumen size could be controlled by varying the distance between cell deposition and, thus, the cell density per unit area. However, these HUVEC networks were unstable and dissociated after a few days in culture, which could be prevented by depositing juxtaposed SMCs 1 day after HUVEC printing. Despite the accuracy attained with a LAB setup, the resulting construct was still too thin for use in a clinical setting. In another report, these authors showed that thicker scaffolds $(300 \mu \mathrm{m})$ could be built by printing HUVECs on top of porous poly(DL-lactide-co-glycolide) biopaper coated with Matrigel. ${ }^{102}$ Stacking these layers into a thick and functional construct that can be perfused remains to be demonstrated. Despite these successes, LAB suffers from several issues, such as the generation of metallic residues during printing, inhomogeneous cell deposition, and long process duration.

Lastly, optical trapping systems can be used as vessel assembly tools by allowing the contactless manipulation of individual vascular-specific cells into defined positions. Compared to the above-mentioned techniques, optical systems offer unmatched precision to control cell location, a great benefit when recreating the multicellular context of vasculature and surrounding tissues. Hocheng et al. provided the proof-ofconcept for optical trapping: endothelial cells were guided by laser through microchannels toward a construction area, where cells could be entrapped by laser tweezers and moved in the horizontal or vertical axis. ${ }^{103}$ Some efforts have been made to further develop this technology, such as inclusion of biomaterials and perfusion systems, to make it a viable technique.

\section{ADDRESSING LIMITATIONS}

Despite substantial progress over the past ten years in the vascularization of biomaterials and artificial tissues, obstacles still remain to produce viable, complex and large implants. We have a working understanding of the major signaling molecules, necessary cell types, and ECM properties that both inhibit and promote vascularization. However, the majority of these studies address only the beginning of a complex problem. How do we control the vascularization of multicellular engineered tissue? Within this framework, we propose that three major limitations remain:

(1) scalability of prevascularized multicellular engineered tissues

(2) directing and connecting vascular networks of multiple length scale

(3) directing vascularization in the presence of other cell types

As researchers continue to strive to find the best engineering solution for organ assembly and vascularization, a synergy of technologies will be likely required to overcome existing limitations (Figure 1e). The combined development materials and fabrication strategies will be essential in addressing these issues, with a number of existing examples shown in Figure 5. This is clearly evident in microfluidic approaches, which have provided powerful tools to simplistically decode physiological processes and assemble tissue functional units (e.g lung-on-achip $^{104}$, liver sinusoid-on-a-chip ${ }^{105}$ ) but have failed to reproduce the native microarchitecture, spatial heterogeneity, and cell-matrix interactions. ${ }^{106}$

To recreate multicellular structures with high fidelity, Sarveswaran et al. recently showcased a combined approach to build a human capillary. ${ }^{106}$ Using live cell lithography, vascular cells were entrapped in photopolymerizable hydrogels to create living voxels, which could be stitched together into a single structure. The cell positioning, ratio between different cell types, and embedding material could be finely tuned in order to recreate the cellular architecture and mechanistic environment present in a human blood vessel. This method provided an unprecedented control for the generation of TE constructs, albeit at a much lower scale than the required to create whole organs (Figure $5 b$ ). Zhang et al. have also showcased an elegant microfluidic platform to assemble miniature vascularized and functional tissues. ${ }^{107}$ Referred to as the AngioChip, this engineered platform combines a 3D biodegradable and porous scaffold with a classic microfluidic chip. A 3D stamped poly(octamethylene maleate (anhydridre) citrate) (POMaC) microchannel network is assembled within the chip and perfused with endothelial cells in order to form built-in patterned vasculature. Surrounding this rigid structure, a cell-loaded ECM gel (collagen/Matrigel mixture or fibrin) forms the parenchymal space. Several combinations of the vascular phase and involving medium can be achieved, making this a highly versatile platform for organ-on-a-chip engineering. This concept was applied to build a liver construct with drug metabolizing capability and a contractile cardiac tissue responsive to chronotropic stimuli (epinephrine injection). Surgical anastomosis of the chip showcased the ability to sustain native blood circulation and the scalability of this platform to create a human-sized constructs, unique for a microfluidic approach.

With respect to scalability, 3D bioprinting techniques are more advantageous and still allow for an easier custom-design fabrication. An example of this is demonstrated by Kang et al., who devised a $3 \mathrm{D}$ printing system incorporating cell-laden hydrogels, sacrificial hydrogels, and biodegradable solid polymers to yield human-scaled tissue constructs with anatomical shape and mechanical integrity. Bone and skeletal muscle tissue replacements were fabricated and implanted, but vascularization within the constructs still relied on capillary invasion from the host, which limits the applicability of this system. ${ }^{1}$ As previously discussed, other works have already demonstrated the potential of $3 \mathrm{D}$ printing techniques to pattern vasculature, either through fabrication of vessel templates and subsequent endothelialization ${ }^{10,108}$ or direct deposition of cells. ${ }^{95}$ In a mixed approach, Lee et al. bioprinted a layer of HUVECs/gelatin mixture between a collagen support, which was thereafter liquefied and perfused, leaving behind a cell lining at the materials interface ${ }^{109}$ (Figure 5a). Addressing the need for multiscale vessels within TE constructs, the same authors reported a variation of this method, by printing and perfusing two large parallel vessels separated by a HUVEC/fibrin mixture, where microvessels spontaneously assembled and integrated with the parent vessels. $^{110}$ 
Despite these advances, 3D bioprinting techniques can also benefit from improvements during the printing process. Although typically a single hydrogel material is used as a cell carrier, Colosi et al. devised an ingenious system that connects a coaxial nozzle to a microfluidic printhead where two different materials can flow, thus allowing for heterogenic fiber deposition. ${ }^{111}$ A HUVEC-loaded GelMA/alginate bioink was extruded through the inner nozzle and cross-linked via calcium chloride flow from the outer nozzle and postprinting UV irradiation. Over culture time, endothelial tubular structures formed as alginate dissolves within the bulk of cross-linked GelMA and cells migrate toward the periphery.

Although the existing palette of bioinks offers several possibilities, the development of new extrudable materials, such as polymers that form dynamic molecular networks, will significantly contribute to progress. An example are supramolecular hydrogels, which have been recently investigated in 3D printing applications, mainly due to their interesting characteristics such as shear-thinning and self-healing ability. The spider silk hydrogels reported by Schacht et al. ${ }^{112}$ or the guest-host HA hydrogels developed by Burdick's group ${ }^{113}$ provide good illustrations of this new materials with reversible supramolecular interactions. Using the latter hydrogels, the ability to print cell-laden layers into a cell-containing selfhealing construct was demonstrated ${ }^{114}$ (Figure 5c). Within this approach, the authors showed the possibility to print connecting networks and to perfuse these printed networks, if desired. Through direct printing within hydrogels, intricate structures such as overhangs can be designed and held in place, in contrast to classical bioprinting where the fluid-air interface would lead to material collapse. Systems of supporting hydrogels to accommodate printed inks are not restricted to supramolecular materials, and others examples include alginate, fibrin, or collagen in a gelatin support ${ }^{115}$ or collagen in a Carbopol granular medium. ${ }^{116}$

One of the most significant hurdles in recapitulating and mimicking the vascularization of natural tissues is the control needed to create an open vascular network over multiple length scales. Small scale of microvessels lie beyond the resolution of physical patterning techniques, leading researchers to harness the highly complex process of neovascularization as it occurs in vivo. Although we are only beginning to unravel mechanisms to direct it within an engineered tissue, a promising strategy is to rely on gradients within materials or materials patterning for the direction of capillary formation. Currently, a limited number of materials can be tailored for vascularization control in 3D. PEGbased systems dominate the studies due mainly to their ease of synthesis and synthetic addressability. Unfortunately, PEG acrylate systems are not always ideal, especially when attempting to combine multiple fabrication methods. Novel approaches to create hydrogels based on more biomimetic networks including noncovalent interactions, self-assembled structures, and reversible covalent bonds can all overcome the limitations of a static covalent network.

Although these strategies can create small-scale vascular networks that are perfusable and highly distributed for ideal distribution of nutrients and oxygen, ${ }^{117}$ connecting such networks to an organism's vasculature remains a challenge; recent studies have shown that natural anastomosis of prevascularized implants results in a 7-day delay in functional blood flow. ${ }^{52,118}$ This is attributed to the time-consuming "wrapping and tapping" process of anastomosis ${ }^{119}$ and subsequent delays associated with the clearance of blood clots that result from initial contact between the host blood and prevascularized vessels. ${ }^{52}$ A more rapid approach is to surgically anastomosize engineered vasculature, which has been reported as a viable option to rapidly promote integration with host vasculature. ${ }^{120,121}$ While immediate blood flow can be established, this requires a suitably sized vessel in order to be compatible with the surgical procedure. Therefore, in order to ensure viability and function of an implanted tissue construct, a designed interconnected vasculature will be required that spans many orders of magnitude.

The ability to control the vascularization of a tissue or material in the presence of multiple cell types remains to be demonstrated. Patterning and/or gradients of VEGF remain a promising strategy for direction of solely vascular formation. Little is known about the effects of controlling vascularization with coculture of other cell types. This is a promising new area of research that can give great insight into the regeneration of complex tissue. Future research will certainly elucidate how to efficiently blend technologies and material resources in this quest for tissue and organ replacements.

\section{FUTURE OUTLOOK}

While some of the fabrication methods reviewed here require specialized technological expertise and equipment, many of the strategies are robust with low technical overhead. This includes the facile method for microvessel patterning using a sacrificial template of micromolded gelatin ${ }^{87}$ as well as the production of microvascular spheroids and their assembly into larger vascular structures. Prompted by the scientific opportunities of "designer" vascular architecture, we foresee the widespread adoption of these platforms through a combination of further simplification of the fabrication processes and commercial availability, mirroring the proliferation of microfluidic technology. Similar to the introduction of 3D assays over 30 years ago, ${ }^{122}$ these tools will allow us to further elucidate the vascularization process under more controlled conditions to provide both scientific insight as well as strategies to address diseased or damaged tissues. In particular, methods able to design endothelialized channel structures within a 3D multicellular context provide a new way to study the interactions between the vascular system and other cell types or tissues. This includes investigating pathologies: designed vascular models have facilitated the study of extravasation and intravasation processes that enable cancer cells to penetrate the vascular wall and metastasize. ${ }^{123,124}$ Impaired interactions between vasculature and the nervous system have also been implicated in certain pathological disorders, ${ }^{125}$ including the role of disrupted cerebral neurovascular coupling in the progression of Alzheimer's disease. ${ }^{126}$ Current methods to study this neurovascular coupling rely on in vivo models, explanted cortical tissues, or dissociated in vitro cultures, providing fertile ground for the development of multicellular vascularized platforms as described in this review.

As these techniques evolve, the most immediate clinical impact will come from a combination of methods to create a meaningful, multiscale vascularization strategy for tissue engineering and regenerative medicine. An ideal combination of micron-sized capillaries (achieved with "smart" materials) with highly arborized 3D distribution of slight larger microvessels (via $3 \mathrm{D}$ cell printing) will ensure sufficient delivery of nutrients; larger connected structures on the millimeter scale (formed by molding techniques) would provide an ideal means of surgically connecting this vascular tree to the blood supply of 

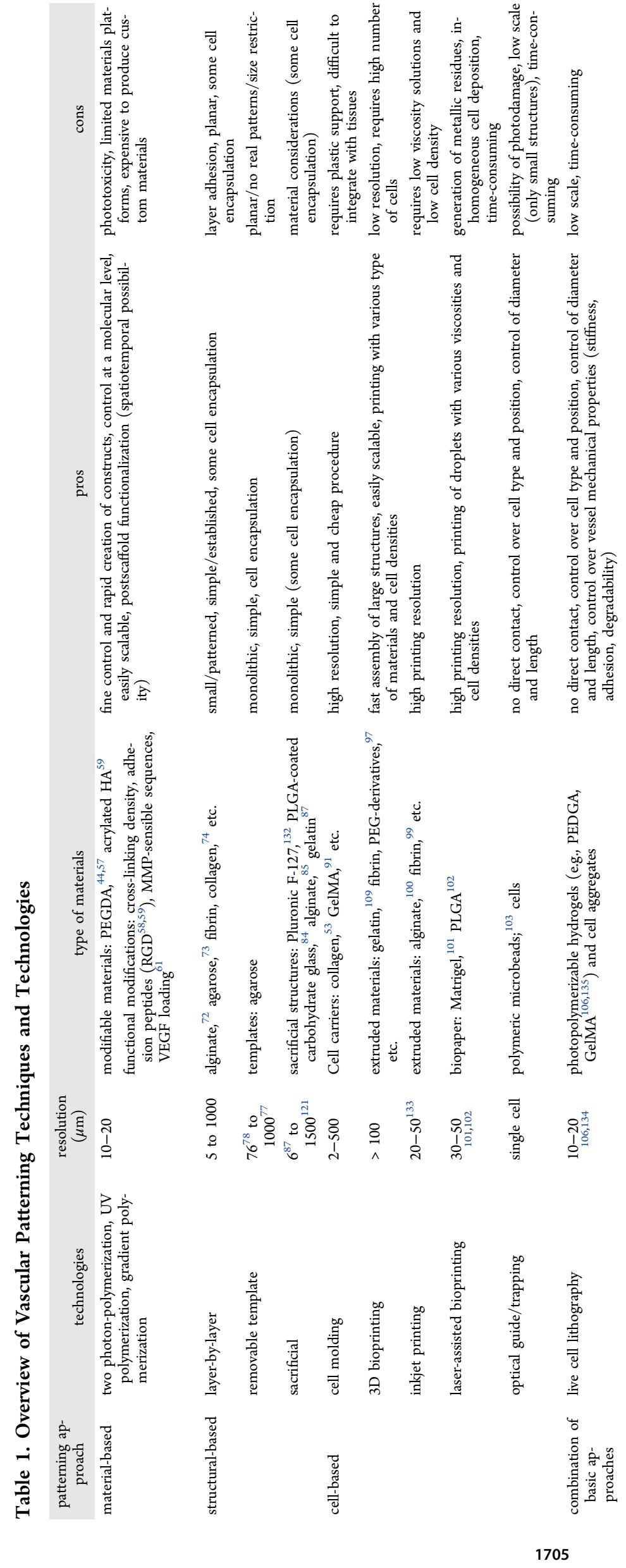
a patient. The ability to control the size and placement of these vascular structures will also ensure proportioned blood flow throughout. Initial steps toward such combinatorial approaches have been showcased. ${ }^{127}$

The advent of more advanced 3D printing technology will usher in immense potential within the biological and biomedical sciences. As technology and materials continue to evolve, we come closer to emulating the biological complexities we observe in vivo. A major limitation in realizing these more advanced printing technologies is the lack of suitable printable materials to control and mimic the natural ECM. Only a few well-characterized synthetic hydrogel systems exist, while many are in their infancy of development. In particular, the dynamic environment of the ECM is often lost in static, covalent polymer hydrogels. Current advances in supramolecular hydrogels and those formed by dynamic covalent chemistry will provide new opportunities for self-healing materials that will allow temporal control of hydrogel properties. With new dynamic gel systems, "smart" materials will introduce dynamic 3D printing, whereby complex multicellular organization can be realized in both a spatial and temporal manner. This advance will enable maturation of vasculature, which is more effective when the inclusion of mural cells is delayed, ${ }^{128}$ followed by the introduction of functional cellular assemblies once the vascular nutrient supply has been established. This also sets the stage for actively recreating time-dependent developmental and selforganizing processes, such as those observed for bone ${ }^{129}$ and cartilage. ${ }^{130}$

The creation of appropriate vascular networks has long been identified as the challenge that underpins the success of any potential TE strategy. As described above and summarized in Table 1, numerous approaches have been developed toward meeting this challenge. The vascular network is one but of many within the body. While it has become the most popular, neural network regeneration, hepatic portal regeneration, and kidney network regeneration can all benefit from the strategies developed around neovascularization. Without the successful control and engineering of the underlying networks that enable viable tissue, TE and RM cannot progress. Furthermore, the development of increasingly powerful and flexible technological solutions extend far beyond simple vascularization, paving the way to the formation of functional tissues and, eventually, whole organs.

\section{AUTHOR INFORMATION}

\section{Corresponding Author}

*E-mail: 1.moroni@maastrichtuniversity.nl.

\section{Author Contributions}

${ }^{\dagger}$ A.M. and P.W. contributed equally to this manuscript.

\section{Notes}

The authors declare no competing financial interest.

\section{REFERENCES}

(1) Kang, H.-W.; Lee, S. J.; Ko, I. K.; Kengla, C.; Yoo, J. J.; Atala, A. A 3D bioprinting system to produce human-scale tissue constructs with structural integrity. Nat. Biotechnol. 2016, 34 (3), 312-322.

(2) MacNeil, S. Biomaterials for tissue engineering of skin. Mater. Today 2008, 11 (5), 26-35.

(3) Atala, A.; Bauer, S. B.; Soker, S.; Yoo, J. J.; Retik, A. B. Tissueengineered autologous bladders for patients needing cystoplasty. Lancet 2006, 367 (9518), 1241-1246.

(4) Chen, X.; Aledia, A. S.; Ghajar, C. M.; Griffith, C. K.; Putnam, A. J.; Hughes, C. C. W.; George, S. C. Prevascularization of a fibrin-based tissue construct accelerates the formation of functional anastomosis with host vasculature. Tissue Eng., Part A 2009, 15 (6), 1363-1371.

(5) Visconti, R. P.; Kasyanov, V.; Gentile, C.; Zhang, J.; Markwald, R. $\mathrm{R}$; Mironov, $\mathrm{V}$. Towards organ printing: engineering an intra-organ branched vascular tree. Expert Opin. Biol. Ther. 2010, 10 (3), 409-420.

(6) Rouwkema, J.; Rivron, N. C.; van Blitterswijk, C. A. Vascularization in tissue engineering. Trends Biotechnol. 2008, 26 (8), 434-441.

(7) Nichol, J. W.; Khademhosseini, A. Modular tissue engineering: Engineering biological tissues from the bottom up. Soft Matter 2009, 5 (7), 1312-1319.

(8) Guillotin, B.; Guillemot, F. Cell patterning technologies for organotypic tissue fabrication. Trends Biotechnol. 2011, 29 (4), 183190.

(9) Levenberg, S.; Rouwkema, J.; Macdonald, M.; Garfein, E. S.; Kohane, D. S.; Darland, D. C.; Marini, R.; van Blitterswijk, C. A.; Mulligan, R. C.; D’Amore, P. A.; Langer, R. Engineering vascularized skeletal muscle tissue. Nat. Biotechnol. 2005, 23 (7), 879-884.

(10) Kolesky, D. B.; Homan, K. A.; Skylar-Scott, M. A.; Lewis, J. A. Three-dimensional bioprinting of thick vascularized tissues. Proc. Natl. Acad. Sci. U. S. A. 2016, 113 (12), 3179-3184.

(11) Suuronen, E. J.; McLaughlin, C. R; Stys, P. K.; Nakamura, M.; Munger, R.; Griffith, M. Functional innervation in tissue engineered models for in vitro study and testing purposes. Toxicol. Sci. 2004, 82 (2), 525-533.

(12) Marx, V. Tissue engineering: Organs from the lab. Nature 2015, 522 (7556), 373-377.

(13) Hariharan, K.; Kurtz, A.; Schmidt-Ott, K. M. Assembling Kidney Tissues from Cells: The Long Road from Organoids to Organs Front. Cell Dev. Biol. 2015, 3, DOI: 10.3389/fcell.2015.00070.

(14) Xinaris, C.; Brizi, V.; Remuzzi, G. Organoid Models and Applications in Biomedical Research. Nephron 2015, 130 (3), 191199.

(15) Novosel, E. C.; Kleinhans, C.; Kluger, P. J. Vascularization is the key challenge in tissue engineering. Adv. Drug Delivery Rev. 2011, 63 (4), 300-311.

(16) McGuigan, A. P.; Sefton, M. V. Vascularized organoid engineered by modular assembly enables blood perfusion. Proc. Natl. Acad. Sci. U. S. A. 2006, 103 (31), 11461-11466.

(17) Baptista, P. M.; Siddiqui, M. M.; Lozier, G.; Rodriguez, S. R.; Atala, A.; Soker, S. The use of whole organ decellularization for the generation of a vascularized liver organoid. Hepatology 2011, 53 (2), 604-617.

(18) van Blitterswijk, C.; Jan de Boer Tissue Engineering. In Tissue Engineering; Elsevier: Amsterdam, 2015.

(19) Potente, M.; Gerhardt, H.; Carmeliet, P. Basic and therapeutic aspects of angiogenesis. Cell 2011, 146 (6), 873-887.

(20) Risau, W. Mechanisms of angiogenesis. Nature 1997, 386 (6626), 671-674.

(21) Carmeliet, P. Mechanisms of angiogenesis and arteriogenesis. Nat. Med. 2000, 6 (4), 389-395.

(22) Bussolino, F.; Mantovani, A.; Persico, G. Molecular mechanisms of blood vessel formation. Trends Biochem. Sci. 1997, 22 (7), 251-256.

(23) Patan, S. Vasculogenesis and angiogenesis as mechanisms of vascular network formation, growth and remodeling. J. Neuro-Oncol. 2000, 50 (1-2), 1-15.

(24) Rouwkema, J.; Khademhosseini, A. Vascularization and Angiogenesis in Tissue Engineering: Beyond Creating Static Networks. Trends Biotechnol. 2016, 1-13.

(25) Blinder, Y. J.; Freiman, A.; Raindel, N.; Mooney, D. J.; Levenberg, S. Vasculogenic dynamics in $3 \mathrm{D}$ engineered tissue constructs. Sci. Rep. 2015, 5, 17840.

(26) Carmeliet, P. Blood vessels and nerves: common signals, pathways and diseases. Nat. Rev. Genet. 2003, 4 (9), 710-720.

(27) Pardali, E.; Goumans, M. J.; ten Dijke, P. Signaling by members of the TGF- $\beta$ family in vascular morphogenesis and disease. Trends Cell Biol. 2010, 20 (9), 556-567. 
(28) Chan, J. M.; Zervantonakis, I. K.; Rimchala, T.; Polacheck, W. J.; Whisler, J.; Kamm, R. D. Engineering of In Vitro 3D Capillary Beds by Self-Directed Angiogenic Sprouting. PLoS One 2012, 7 (12), e50582. (29) Eckermann, C. W.; Lehle, K.; Schmid, S. a.; Wheatley, D. N.; Kunz-Schughart, L. a. Characterization and modulation of fibroblast/ endothelial cell co-cultures for the in vitro preformation of threedimensional tubular networks. Cell Biol. Int. 2011, 35 (11), 10971110.

(30) Baldwin, J.; Antille, M.; Bonda, U.; De-juan-pardo, E. M.; Khosrotehrani, K.; Ivanovski, S.; Petcu, E. B.; Hutmacher, D. W. In vitro pre-vascularisation of tissue-engineered constructs A co-culture perspective. Vasc. Cell 2014, 6 (13), DOI: 10.1186/2045-824X-6-13.

(31) Cheng, C.-C.; Chang, S.-J.; Chueh, Y.-N.; Huang, T.-S.; Huang, P.-H.; Cheng, S.-M.; Tsai, T.-N.; Chen, J.-W.; Wang, H.-W. Distinct angiogenesis roles and surface markers of early and late endothelial progenitor cells revealed by functional group analyses. BMC Genomics 2013, 14 (1), 182.

(32) Chen, X.; Aledia, A. S.; Popson, S. a; Him, L.; Hughes, C. C. W.; George, S. C. Rapid anastomosis of endothelial progenitor cell-derived vessels with host vasculature is promoted by a high density of cotransplanted fibroblasts. Tissue Eng., Part A 2010, 16 (2), 585-594. (33) Armulik, A.; Genove, G.; Betsholtz, C. Pericytes: Developmental, Physiological, and Pathological Perspectives, Problems, and Promises. Dev. Cell 2011, 21, 193-215.

(34) Blinder, Y.; Mooney, D.; Levenberg, S. Engineering approaches for inducing blood vessel formation. Curr. Opin. Chem. Eng. 2014, 3, 56-61.

(35) Chwalek, K.; Tsurkan, M. V.; Freudenberg, U.; Werner, C. Glycosaminoglycan-based hydrogels to modulate heterocellular communication in in vitro angiogenesis models. Sci. Rep. 2014, 4, 4414.

(36) Goodwin, A. M. In vitro assays of angiogenesis for assessment of angiogenic and anti-angiogenic agents. Microvasc. Res. 2007, 74 (2-3), $172-183$.

(37) Donovan, D.; Brown, N. J.; Bishop, E. T.; Lewis, C. E. Comparison of three in vitro human "angiogenesis" assays with capillaries formed in vivo. Angiogenesis 2001, 4 (2), 113-121.

(38) Moon, J. J.; Saik, J. E.; Poche, R. A.; Leslie-Barbick, J. E.; Lee, S. H.; Smith, A. A.; Dickinson, M. E.; West, J. L. Biomimetic hydrogels with pro-angiogenic properties. Biomaterials 2010, 31 (14), 38403847.

(39) Sacharidou, A.; Koh, W.; Stratman, A. N.; Mayo, A. M.; Fisher, K. E.; Davis, G. E. Endothelial lumen signaling complexes control 3D matrix - specific tubulogenesis through interdependent Cdc42- and MT1-MMP - mediated events. Blood 2010, 115 (25), 5259-5269.

(40) Ghajar, C. M.; Blevins, K. S.; Hughes, C. C. W.; George, S. C.; Putnam, A. J. Mesenchymal stem cells enhance angiogenesis in mechanically viable prevascularized tissues via early matrix metalloproteinase upregulation. Tissue Eng. 2006, 12 (10), 2875-2888.

(41) Darland, D. C.; D'Amore, P. A. TGFb is required for the formation of capillary-like structures in three-dimensional cocultures of 10T1/2 and endothelial cells. Angiogenesis 2001, 4, 11-20.

(42) Phelps, E. A.; Headen, D. M.; Taylor, W. R.; Thulé, P. M.; García, A. J. Vasculogenic bio-synthetic hydrogel for enhancement of pancreatic islet engraftment and function in type 1 diabetes. Biomaterials 2013, 34 (19), 4602-4611.

(43) Leslie-Barbick, J. E.; Moon, J. J.; West, J. L. Covalentlyimmobilized vascular endothelial growth factor promotes endothelial cell tubulogenesis in poly(ethylene glycol) diacrylate hydrogels. J. Biomater. Sci., Polym. Ed. 2009, 20 (12), 1763-1779.

(44) Leslie-Barbick, J. E.; Saik, J. E.; Gould, D. J.; Dickinson, M. E.; West, J. L. The promotion of microvasculature formation in poly(ethylene glycol) diacrylate hydrogels by an immobilized VEGFmimetic peptide. Biomaterials 2011, 32 (25), 5782-5789.

(45) Briquez, P. S.; Clegg, L. E.; Martino, M. M.; Gabhann, F. M.; Hubbell, J. A. Design principles for therapeutic angiogenic materials. Nat. Rev. Mater. 2016, 1 (1), 15006.
(46) Birbrair, A.; Zhang, T.; Wang, Z.-M.; Messi, M. L.; Mintz, A.; Delbono, O. Pericytes at the intersection between tissue regeneration and pathology. Clin. Sci. 2015, 128 (2), 81-93.

(47) Blacher, S.; Erpicum, C.; Lenoir, B.; Paupert, J.; Moraes, G.; Ormenese, S.; Bullinger, E.; Noel, A. Cell invasion in the spheroid sprouting assay: A spatial organisation analysis adaptable to cell behaviour. PLoS One 2014, 9 (5), e97019.

(48) Lovett, M.; Lee, K.; Edwards, A.; Kaplan, D. L. Vascularization strategies for tissue engineering. Tissue Eng., Part B 2009, 15 (3), 353370.

(49) Laschke, M. W.; Menger, M. D. Prevascularization in tissue engineering: Current concepts and future directions. Biotechnol. Adv. 2016, 34 (2), 112-121.

(50) Atluri, P.; Miller, J. S.; Emery, R. J.; Hung, G.; Trubelja, A.; Cohen, J. E.; Lloyd, K.; Han, J.; Gaffey, A. C.; Macarthur, J. W.; et al. Tissue-engineered, hydrogel-based endothelial progenitor cell therapy robustly revascularizes ischemic myocardium and preserves ventricular function. J. Thorac. Cardiovasc. Surg. 2014, 148 (3), 1090-1098.

(51) Buitinga, M.; Janeczek Portalska, K.; Cornelissen, D.-J.; Plass, J.; Hanegraaf, M.; Carlotti, F.; de Koning, E.; Engelse, M. A.; van Blitterswijk, C.; Karperien, M.; van Apeldoorn, A.; de Boer, J. Coculturing human islets with proangiogenic support cells to improve islet revascularization at the subcutaneous transplantation site. Tissue Eng., Part A 2016, 22, 375-385.

(52) White, S. M.; Pittman, C. R.; Hingorani, R.; Arora, R.; Esipova, T. V.; Vinogradov, S. A.; Hughes, C. C. W.; Choi, B.; George, S. C. Implanted Cell-Dense Prevascularized Tissues Develop Functional Vasculature that Supports Reoxygenation Following Thrombosis. Tissue Eng., Part A 2014, 20, 2316-2328.

(53) Baranski, J. D.; Chaturvedi, R. R.; Stevens, K. R.; Eyckmans, J.; Carvalho, B.; Solorzano, R. D.; Yang, M. T.; Miller, J. S.; Bhatia, S. N.; Chen, C. S. Geometric control of vascular networks to enhance engineered tissue integration and function. Proc. Natl. Acad. Sci. U. S. A. 2013, 110 (19), 7586-7591.

(54) White, S. M.; Hingorani, R.; Arora, R. P. S.; Hughes, C. C. W.; George, S. C.; Choi, B. Imaging to Assess Blood Flow and Oxygenation in Implantable Engineered Tissues. Tissue Eng., Part $C$ 2012, 18 (9), 697-709.

(55) Kucukgul, C.; Ozler, B.; Karakas, H. E.; Gozuacik, D.; Koc, B. 3D hybrid bioprinting of macrovascular structures. Procedia Eng. 2013, 59, 183-192.

(56) Leslie-Barbick, J. E.; Shen, C.; Chen, C.; West, J. L. Micron-scale spatially patterned, covalently immobilized vascular endothelial growth factor on hydrogels accelerates endothelial tubulogenesis and increases cellular angiogenic responses. Tissue Eng., Part A 2011, 17 (1-2), 221-229.

(57) Culver, J. C.; Hoffmann, J. C.; Poche, R. A.; Slater, J. H.; West, J. L.; Dickinson, M. E.; Poche, R. A.; Slater, J. H.; West, J. L.; Dickinson, M. E. Three-dimensional biomimetic patterning in hydrogels to guide cellular organization. Adv. Mater. 2012, 24 (17), 2344-2348.

(58) Lee, T. T.; García, J. R.; Paez, J. I.; Singh, A.; Phelps, E. A.; Weis, S.; Shafiq, Z.; Shekaran, A.; Del Campo, A.; García, A. J. Lighttriggered in vivo activation of adhesive peptides regulates cell adhesion, inflammation and vascularization of biomaterials. Nat. Mater. 2015, 14 (3), 352-360.

(59) Hanjaya-Putra, D.; Wong, K. T.; Hirotsu, K.; Khetan, S.; Burdick, J. A.; Gerecht, S. Spatial control of cell-mediated degradation to regulate vasculogenesis and angiogenesis in hyaluronan hydrogels. Biomaterials 2012, 33 (26), 6123-6131.

(60) Sokic, S.; Christenson, M. C.; Larson, J. C.; Appel, A. A.; Brey, E. M.; Papavasiliou, G. Evaluation of MMP substrate concentration and specificity for neovascularization of hydrogel scaffolds. Biomater. Sci. 2014, 2 (10), 1343.

(61) Turturro, M. V.; Christenson, M. C.; Larson, J. C.; Young, D. A.; Brey, E. M.; Papavasiliou, G. MMP-Sensitive PEG Diacrylate Hydrogels with Spatial Variations in Matrix Properties Stimulate Directional Vascular Sprout Formation. PLoS One 2013, 8 (3), e58897. 
(62) Akar, B.; Jiang, B.; Somo, S. I.; Appel, A. A.; Larson, J. C.; Tichauer, K. M.; Brey, E. M. Biomaterials with persistent growth factor gradients in vivo accelerate vascularized tissue formation. Biomaterials 2015, 72, 61-73.

(63) Aizawa, Y.; Wylie, R.; Shoichet, M. Endothelial cell guidance in 3D patterned scaffolds. Adv. Mater. 2010, 22 (43), 4831-4835.

(64) Park, K. M.; Gerecht, S. Hypoxia-inducible hydrogels. Nat. Commun. 2014, 5 (May), 1-12.

(65) Kim, P.; Kwon, K. W.; Park, M. C.; Lee, S. H.; Kim, S. M. Soft Lithography for Microfluidics: a Review. Biochip J. 2008, 2 (1), 1-11.

(66) Smith, Q.; Gerecht, S. Going with the flow: Microfluidic platforms in vascular tissue engineering. Curr. Opin. Chem. Eng. 2014, $3,42-50$.

(67) Vickerman, V.; Chung, S.; Kamm, R. D. Design, Fabrication and Implementation of a Novel Multi Parameter Control Microfluidic Platform for Three-Dimensional Cell Culture and Real-Time Imaging. Lab Chip 2008, 8 (9), 1468-1477.

(68) Jeon, J. S.; Bersini, S.; Whisler, J. a; Chen, M. B.; Dubini, G.; Charest, J. L.; Moretti, M.; Kamm, R. D. Generation of 3D functional microvascular networks with human mesenchymal stem cells in microfluidic systems. Integr. Biol. (Camb). 2014, 6 (5), 555-563.

(69) van der Meer, A. D.; Orlova, V. V.; ten Dijke, P.; van den Berg, A.; Mummery, C. L. Three-dimensional co-cultures of human endothelial cells and embryonic stem cell-derived pericytes inside a microfluidic device. Lab Chip 2013, 13, 3562-3568.

(70) Cuchiara, M. P.; Gould, D. J.; McHale, M. K.; Dickinson, M. E.; West, J. L. Integration of self-assembled microvascular networks with microfabricated PEG-based hydrogels. Adv. Funct. Mater. 2012, 22 (21), 4511-4518.

(71) Hsu, Y.-H.; Moya, M. L.; Hughes, C. C. W.; George, S. C.; Lee, A. P. A microfluidic platform for generating large-scale nearly identical human microphysiological vascularized tissue arrays. Lab Chip 2013, 13 (15), 2990-2998.

(72) Cabodi, M.; Choi, N. W.; Gleghorn, J. P.; Lee, C. S. D.; Bonassar, L. J.; Stroock, A. D. A microfluidic biomaterial. J. Am. Chem. Soc. 2005, 127 (40), 13788-13789.

(73) Ling, Y.; Rubin, J.; Deng, Y.; Huang, C.; Demirci, U.; Karp, J. M.; Khademhosseini, A. A cell-laden microfluidic hydrogel. Lab Chip 2007, 7 (6), 756-762.

(74) Price, G. M.; Chu, K. K.; Truslow, J. G.; Tang-Schomer, M. D.; Golden, A. P.; Mertz, J.; Tien, J. Bonding of macromolecular hydrogels using perturbants. J. Am. Chem. Soc. 2008, 130 (21), 6664-6665.

(75) Choi, N. W.; Cabodi, M.; Held, B.; Gleghorn, J. P.; Bonassar, L. J.; Stroock, A. D. Microfluidic scaffolds for tissue engineering. Nat. Mater. 2007, 6 (11), 908-915.

(76) Sakaguchi, K.; Shimizu, T.; Horaguchi, S.; Sekine, H.; Yamato, M.; Umezu, M.; Okano, T. In vitro engineering of vascularized tissue surrogates. Sci. Rep. 2013, 3, 1316.

(77) Nichol, J. W.; Koshy, S. T.; Bae, H.; Hwang, C. M.; Yamanlar, S.; Khademhosseini, A. Cell-laden microengineered gelatin methacrylate hydrogels. Biomaterials 2010, 31 (21), 5536-5544.

(78) Vernon, R. B.; Gooden, M. D.; Lara, S. L.; Wight, T. N. Native fibrillar collagen membranes of micron-scale and submicron thicknesses for cell support and perfusion. Biomaterials 2005, 26 (10), 1109-1117.

(79) Bertassoni, L. E.; Cecconi, M.; Manoharan, V.; Nikkhah, M.; Hjortnaes, J.; Cristino, A. L.; Barabaschi, G.; Demarchi, D.; Dokmeci, M. R.; Yang, Y.; Khademhosseini, A. Hydrogel bioprinted microchannel networks for vascularization of tissue engineering constructs. Lab Chip 2014, 14 (13), 2202-2211.

(80) Jiménez-Torres, J. A.; Peery, S. L.; Sung, K. E.; Beebe, D. J. LumeNEXT: A Practical Method to Pattern Luminal Structures in ECM Gels. Adv. Healthcare Mater. 2016, 5 (2), 198-204.

(81) Bellan, L. M.; Pearsall, M.; Cropek, D. M.; Langer, R. A 3D interconnected microchannel network formed in gelatin by sacrificial shellac microfibers. Adv. Mater. 2012, 24 (38), 5187-5191.

(82) Tocchio, A.; Tamplenizza, M.; Martello, F.; Gerges, I.; Rossi, E.; Argentiere, S.; Rodighiero, S.; Zhao, W.; Milani, P.; Lenardi, C.
Versatile fabrication of vascularizable scaffolds for large tissue engineering in bioreactor. Biomaterials 2015, 45, 124-131.

(83) Huling, J.; Ko, I. K.; Atala, A.; Yoo, J. J. Fabrication of biomimetic vascular scaffolds for 3D tissue constructs using vascular corrosion casts. Acta Biomater. 2016, 32, 190-197.

(84) Miller, J. S.; Stevens, K. R.; Yang, M. T.; Baker, B. M.; Nguyen, D.-H. T.; Cohen, D. M.; Toro, E.; Chen, A. a.; Galie, P. a.; Yu, X.; et al. Rapid casting of patterned vascular networks for perfusable engineered three-dimensional tissues. Nat. Mater. 2012, 11 (9), 768-774.

(85) Vollert, I.; Seiffert, M.; Bachmair, J.; Sander, M.; Eder, A.; Conradi, L.; Vogelsang, A.; Schulze, T.; Uebeler, J.; Holnthoner, W.; et al. In vitro perfusion of engineered heart tissue through endothelialized channels. Tissue Eng., Part A 2014, 20 (3-4), 854863.

(86) Wang, X.-Y.; Jin, Z.-H.; Gan, B.-W.; Lv, S.-W.; Xie, M.; Huang, W.-H. Engineering interconnected 3D vascular networks in hydrogels using molded sodium alginate lattice as the sacrificial template. Lab Chip 2014, 14 (15), 2709-2716.

(87) Golden, A. P.; Tien, J. Fabrication of microfluidic hydrogels using molded gelatin as a sacrificial element. Lab Chip 2007, 7 (6), $720-725$.

(88) Lee, J. B.; Wang, X.; Faley, S.; Baer, B.; Balikov, D. A.; Sung, H.J.; Bellan, L. M. Development of 3D Microvascular Networks Within Gelatin Hydrogels Using Thermoresponsive Sacrificial Microfibers. Adv. Healthcare Mater. 2016, 5, 781-785.

(89) Kolesky, D. B.; Truby, R. L.; Gladman, A. S.; Busbee, T. A.; Homan, K. A.; Lewis, J. A. 3D bioprinting of vascularized, heterogeneous cell-laden tissue constructs. Adv. Mater. 2014, 26 (19), 3124-3130.

(90) Hoch, E.; Tovar, G. E. M.; Borchers, K. Bioprinting of artificial blood vessels: current approaches towards a demanding goal. Eur. J. Cardiothorac. Surg. 2014, 46 (5), 767-778.

(91) Nikkhah, M.; Eshak, N.; Zorlutuna, P.; Annabi, N.; Castello, M.; Kim, K.; Dolatshahi-Pirouz, A.; Edalat, F.; Bae, H.; Yang, Y.; et al. Directed endothelial cell morphogenesis in micropatterned gelatin methacrylate hydrogels. Biomaterials 2012, 33 (35), 9009-9018.

(92) Mironov, V.; Visconti, R. P.; Kasyanov, V.; Forgacs, G.; Drake, C. J.; Markwald, R. R. Organ printing: Tissue spheroids as building blocks. Biomaterials 2009, 30 (12), 2164-2174.

(93) Fleming, P. A.; Argraves, W. S.; Gentile, C.; Neagu, A.; Forgacs, G.; Drake, C. J. Fusion of uniluminal vascular spheroids: A model for assembly of blood vessels. Dev. Dyn. 2010, 239 (2), 398-406.

(94) Jakab, K.; Norotte, C.; Damon, B.; Marga, F.; Neagu, A.; BeschWilliford, C. L.; Kachurin, A.; Church, K. H.; Park, H.; Mironov, V.; et al. Tissue engineering by self-assembly of cells printed into topologically defined structures. Tissue Eng., Part A 2008, 14 (3), 413421.

(95) Norotte, C.; Marga, F. S.; Niklason, L. E.; Forgacs, G. Scaffoldfree vascular tissue engineering using bioprinting. Biomaterials 2009, 30 (30), 5910-5917.

(96) Skardal, A.; Zhang, J.; McCoard, L.; Xu, X.; Oottamasathien, S.; Prestwich, G. D. Photocrosslinkable Hyaluronan-Gelatin Hydrogels for Two-Step Bioprinting. Tissue Eng., Part A 2010, 16 (8), 26752685.

(97) Skardal, A.; Zhang, J.; Prestwich, G. D. Bioprinting vessel-like constructs using hyaluronan hydrogels crosslinked with tetrahedral polyethylene glycol tetracrylates. Biomaterials 2010, 31 (24), 61736181.

(98) Derby, B. Bioprinting: inkjet printing proteins and hybrid cellcontaining materials and structures. J. Mater. Chem. 2008, 18, 57175721.

(99) Cui, X.; Boland, T. Human microvasculature fabrication using thermal inkjet printing technology. Biomaterials 2009, 30 (31), 62216227.

(100) Christensen, K.; Xu, C.; Chai, W.; Zhang, Z.; Fu, J.; Huang, Y. Freeform inkjet printing of cellular structures with bifurcations. Biotechnol. Bioeng. 2015, 112 (5), 1047-1055.

(101) Wu, P. K.; Ringeisen, B. R. Development of human umbilical vein endothelial cell (HUVEC) and human umbilical vein smooth 
muscle cell (HUVSMC) branch/stem structures on hydrogel layers via biological laser printing (BioLP). Biofabrication 2010, 2, 014111.

(102) Pirlo, R. K.; Wu, P.; Liu, J.; Ringeisen, B. PLGA/hydrogel biopapers as a stackable substrate for printing HUVEC networks via BioLP. Biotechnol. Bioeng. 2012, 109 (1), 262-273.

(103) Hocheng, H.; Tseng, C. Mechanical and optical design for assembly of vascular endothelial cells using laser guidance and tweezers. Opt. Commun. 2008, 281 (17), 4435-4441.

(104) Huh, D.; Matthews, B. D.; Mammoto, A.; Hsin, H. Y.; Ingber, D. E. Reconstituting Organ-Level Lung Functions on a Chip. Science 2010, 328, 1662-1668.

(105) Kang, Y. B. A.; Sodunke, T. R.; Lamontagne, J.; Cirillo, J.; Rajiv, C.; Bouchard, M. J.; Noh, M. Liver sinusoid on a chip: Longterm layered co-culture of primary rat hepatocytes and endothelial cells in microfluidic platforms. Biotechnol. Bioeng. 2015, 112 (12), $2571-2582$.

(106) Sarveswaran, K.; Kurz, V.; Dong, Z.; Tanaka, T.; Penny, S.; Timp, G. Synthetic Capillaries to Control Microscopic Blood Flow. Sci. Rep. 2016, 6, 21885.

(107) Zhang, B.; Montgomery, M.; Chamberlain, M. D.; Ogawa, S.; Korolj, A.; Pahnke, A.; Wells, L. A.; Massé, S.; Kim, J.; Reis, L.; et al. Biodegradable scaffold with built-in vasculature for organ-on-a-chip engineering and direct surgical anastomosis. Nat. Mater. 2016, 1, 669678.

(108) Kolesky, D. B.; Truby, R. L.; Gladman, a. S.; Busbee, T. a.; Homan, K. a.; Lewis, J. a. 3D bioprinting of vascularized, heterogeneous cell-laden tissue constructs. Adv. Mater. 2014, 26 (19), 3124-3130.

(109) Lee, V. K.; Kim, D. Y.; Ngo, H.; Lee, Y.; Seo, L.; Yoo, S. S.; Vincent, P. a.; Dai, G. Creating perfused functional vascular channels using 3D bio-printing technology. Biomaterials 2014, 35, 8092-8102.

(110) Lee, V. K.; Lanzi, A. M.; Ngo, H.; Yoo, S. S.; Vincent, P. A.; Dai, G. Generation of multi-scale vascular network system within 3D hydrogel using 3D bio-printing technology. Cell. Mol. Bioeng. 2014, 7 (3), 460-472.

(111) Colosi, C.; Shin, S. R.; Manoharan, V.; Massa, S.; Costantini, M.; Barbetta, A.; Dokmeci, M. R.; Dentini, M.; Khademhosseini, A. Microfluidic Bioprinting of Heterogeneous 3D Tissue Constructs Using Low-Viscosity Bioink. Adv. Mater. 2016, 28 (4), 677-684a.

(112) Schacht, K.; Jüngst, T.; Schweinlin, M.; Ewald, A.; Groll, J.; Scheibel, T. Biofabrication of Cell-Loaded 3D Spider Silk Constructs. Angew. Chem., Int. Ed. 2015, 54 (9), 2816-2820.

(113) Ouyang, L.; Highley, C. B.; Rodell, C. B.; Sun, W.; Burdick, J. A. 3D Printing of Shear-Thinning Hyaluronic Acid Hydrogels with Secondary Cross-Linking. ACS Biomater. Sci. Eng. 2016, in press; DOI: 10.1021/acsbiomaterials.6b00158.

(114) Highley, C. B.; Rodell, C. B.; Burdick, J. a. Direct 3D Printing of Shear-Thinning Hydrogels into Self-Healing Hydrogels. Adv. Mater. 2015, 27, 5075.

(115) Hinton, T. J.; Jallerat, Q.; Palchesko, R. N.; Park, J. H.; Grodzicki, M. S.; Shue, H.-J.; Ramadan, M. H.; Hudson, A. R.; Feinberg, A. W. Three-dimensional printing of complex biological structures by freeform reversible embedding of suspended hydrogels. Sci. Adv. 2015, 1 (9), e1500758-e1500758.

(116) Bhattacharjee, T.; Zehnder, S. M.; Rowe, K. G.; Jain, S.; Nixon, R. M.; Sawyer, W. G.; Angelini, T. E. Writing in the granular gel medium. Sci. Adv. 2015, 1 (8), e1500655.

(117) Coulombe, K. L. K.; Bajpai, V. K.; Andreadis, S. T.; Murry, C. E. Heart Regeneration with Engineered Myocardial Tissue. Annu. Rev. Biomed. Eng. 2014, 16, 1-28.

(118) Riegler, J.; Gillich, A.; Shen, Q.; Gold, J. D.; Wu, J. C. Cardiac tissue slice transplantation as a model to assess tissue-engineered graft thickness, survival, and function. Circulation 2014, 130 (11), S77-S86.

(119) Cheng, G.; Liao, S.; Kit Wong, H.; Lacorre, D. A.; Di Tomaso, E.; Au, P.; Fukumura, D.; Jain, R. K.; Munn, L. L. Engineered blood vessel networks connect to host vasculature via wrapping-and-tapping anastomosis. Blood 2011, 118 (17), 4740-4749.

(120) Sooppan, R.; Paulsen, S. J.; Han, J.; Ta, A. H.; Dinh, P.; Gaffey, A. C.; Venkataraman, C.; Trubelja, A.; Hung, G.; Miller, J. S.; et al. In
Vivo Anastomosis and Perfusion of a Three-Dimensionally-Printed Construct Containing Microchannel Networks. Tissue Eng., Part C 2016, 22 (1), 1-7.

(121) Hooper, R. C.; Hernandez, K. a; Boyko, T.; Harper, A.; Joyce, J.; Golas, A. R.; Spector, J. a. Fabrication and in vivo microanastomosis of vascularized tissue-engineered constructs. Tissue Eng., Part A 2014, 20 (19-20), 2711-2719.

(122) Montesano, R.; Orci, L.; Vassalli, P. In vitro rapid organization of endothelial cells into capillary-like networks is promoted by collagen matrices. J. Cell Biol. 1983, 97 (5), 1648-1652.

(123) Zervantonakis, I. K.; Hughes-Alford, S. K.; Charest, J. L.; Condeelis, J. S.; Gertler, F. B.; Kamm, R. D. Three-dimensional microfluidic model for tumor cell intravasation and endothelial barrier function. Proc. Natl. Acad. Sci. U. S. A. 2012, 109 (34), 13515-13520.

(124) Bersini, S.; Jeon, J. S.; Dubini, G.; Arrigoni, C.; Chung, S.; Charest, J. L.; Moretti, M.; Kamm, R. D. A Microfluidic 3D In Vitro Model for Specificity of Breast Cancer Metastasis to Bone. Biomaterials 2014, 35 (8), 2454-2461.

(125) Quaegebeur, A.; Lange, C.; Carmeliet, P. The neurovascular link in health and disease: Molecular mechanisms and therapeutic implications. Neuron 2011, 71 (3), 406-424.

(126) Nicolakakis, N.; Hamel, E. Neurovascular function in Alzheimer's disease patients and experimental models. J. Cereb. Blood Flow Metab. 2011, 31 (6), 1354-1370.

(127) Kang, Y.; Mochizuki, N.; Khademhosseini, A.; Fukuda, J.; Yang, Y. Engineering a vascularized collagen-beta-tricalcium phosphate graft using an electrochemical approach. Acta Biomater. 2015, 11 (1), 449-458.

(128) McFadden, T. M.; Duffy, G. P.; Allen, A. B.; Stevens, H. Y.; Schwarzmaier, S. M.; Plesnila, N.; Murphy, J. M.; Barry, F. P.; Guldberg, R. E.; O’Brien, F. J. The delayed addition of human mesenchymal stem cells to pre-formed endothelial cell networks results in functional vascularization of a collagen-glycosaminoglycan scaffold in vivo. Acta Biomater. 2013, 9 (12), 9303-9316.

(129) Bayer, E. A.; Gottardi, R.; Fedorchak, M. V.; Little, S. R. The scope and sequence of growth factor delivery for vascularized bone tissue regeneration. J. Controlled Release 2015, 219, 129-140.

(130) Gadjanski, I.; Spiller, K.; Vunjak-Novakovic, G. Timedependent processes in stem cell-based tissue engineering of articular cartilage. Stem Cell Rev. 2012, 8 (3), 863-881.

(131) Kolesky, D. B.; Homan, K. A.; Skylar-Scott, M. A.; Lewis, J. A. Three-dimensional bioprinting of thick vascularized tissues. Proc. Natl. Acad. Sci. U. S. A. 2016, 113, 3179-3184.

(132) Wu, W.; Deconinck, A.; Lewis, J. a. Omnidirectional printing of 3D microvascular networks. Adv. Mater. 2011, 23 (24), H178-H183.

(133) Derby, B. Inkjet Printing of Functional and Structural Materials: Fluid Property Requirements, Feature Stability, and Resolution. Annu. Rev. Mater. Res. 2010, 40 (1), 395-414.

(134) Linnenberger, A.; Bodine, M. I.; Fiedler, C.; Roberts, J. J.; Skaalure, S. C.; Quinn, J. P.; Bryant, S. J.; Cole, M.; McLeod, R. R; James, C. D.; et al. Three dimensional live cell lithography. Opt. Express 2013, 21, 10269.

(135) Mirsaidov, U.; Scrimgeour, J.; Timp, W.; Beck, K.; Mir, M.; Matsudaira, P.; Timp, G. Live cell lithography: using optical tweezers to create synthetic tissue. Lab Chip 2008, 8 (12), 2174-2181. 